\title{
EFFECTS OF PERFORMANCE-BASED METHODS IN TEACHING OF DIFFERENCE WITH YOUTH
}

\author{
by \\ Madison Elizabeth Gaudry-Routledge \\ Bachelor of Arts, Gender Studies, Political Studies, Queen's University, 2015 \\ A Major Research Paper \\ presented to Ryerson University and York University \\ in partial fulfillment of the \\ requirements for the degree of \\ Master of Arts \\ in the program of \\ Communication and Culture \\ Toronto, Ontario, Canada, 2018 \\ (C) Madison Elizabeth Gaudry-Routledge, 2018
}




\section{Author's Declaration}

I hereby declare that I am the sole author of this MRP. This is a true copy of the MRP, including any required final revisions.

I authorize Ryerson University to lend this MRP to other institutions or individuals for the purpose of scholarly research.

I further authorize Ryerson University to reproduce this MRP by photocopying or by other means, in total or in part, at the request of other institutions or individuals for the purpose of scholarly research.

I understand that my MRP may be made electronically available to the public. 


\begin{abstract}
Master of Arts, 2018

Madison Elizabeth Gaudry-Routledge

Program of Communication and Culture

Ryerson University/York University
\end{abstract}

Effects of Performance-Based Methods in Teaching of Difference with Youth

This qualitative research study explored the pragmatic ways in which youth ages 8 - 17 are taught within the Canadian education system, specifically Ontario, on topics of difference and power and how this influences their understanding of the construction of identity and the systemic oppression of marginalized groups. This study aimed to present findings from four elementary and high school educators and their perceptions of implementing performance-based practices with youth as a critical pedagogical tool in order to address issues surrounding difference. Through semi-structured interviews, these educators described their experiences using these methods in their classroom. Using a thematic analysis, this study revealed several benefits of including performative methods in the educational setting but found that there are a number of challenges that could impede the effective implementation of these practices. Including critical performance-based practices in the classroom has the potential to empower youth as they navigate their identities.

Key Words: oppression, critical pedagogy, social justice, drama education, performative inquiry 


\section{Acknowledgements}

I would like to first and foremost thank my supervisor, Dr. Marni Binder. It is difficult to express the genuine gratitude I have for you and all that you have done for me throughout this process. Your endless support and constant encouragement helped me more than you know. You went above and beyond countless times to ensure that this research was carried out in the way that I had always hoped for. Thank you so much for the invaluable feedback you provided me with, for reassuring me when I needed it the most, and for pushing me to become a better writer along the way. You constantly inspired me with your passion for art, social justice and calming nature. I would also like to sincerely thank Dr. Natalie Coulter for being my second reader and for taking the time to provide me with suggestions to further enhance my research and thoughtful feedback. Thank you for providing me insight into a different side of children's education.

I would also like to thank the four educators who took the time out of their busy schedules to meet with me. Hearing about all of your experiences was a truly life changing experience for me and I am deeply grateful to have gotten the opportunity to speak with you all. Your passion for implementing performance with your students inspires me to continue my research and use these practices with youth in the future.

Lastly, I would like to thank all of the amazing individuals and faculty in the Communication and Culture program. I am so happy to have met such an amazing, fun, and inspiring group of individuals. I wish you all the best of luck in your personal, academic and career endeavors. I know I will be seeing you all very soon. Good luck to all of you! 


\section{Dedications}

I would like to dedicate this Major Research Paper to my family and friends. Thank you

all for supporting me throughout this process with your kind words of encouragement and all of your love. I would especially like to thank the following people:

A special thank you to my grandparents June and Robert Routledge for always keeping an open mind as I expressed my thoughts. You two are the best soundboard anyone could ask for.

To my dearest, closest friends Stephani and Rachel thank you for your amazing support and friendships, especially throughout this process.

To my partner, Ezron, thank you for your endless love and support and reminding me that there is always time.

To my father, Thomas Gaudry, thank you for always reminding me that knowledge is power, making me laugh and pushing me to do my best.

To my mother, Dena Routledge, thank you so much for always being my rock and unconditionally supporting me throughout my entire life. You have always believed in me and have always been there to remind me that the sun will always rise in a mile. 


\section{Table of Contents}

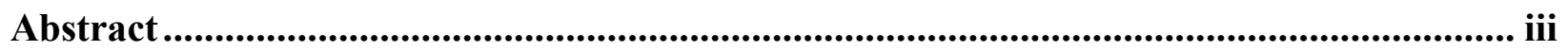

Acknowledgements ..............................................................................................................iv

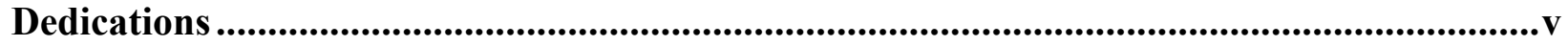

List of Appendices.....................................................................vii

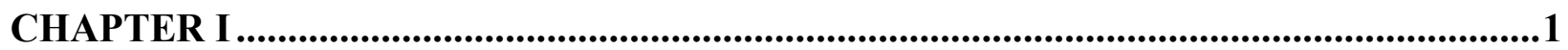

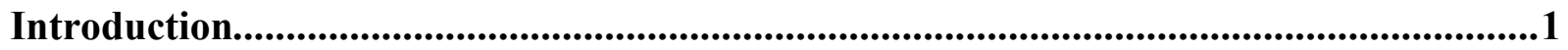

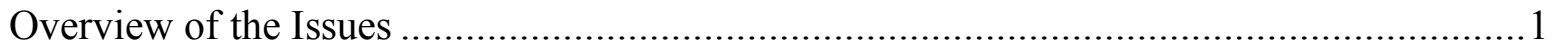

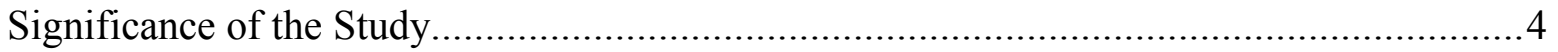

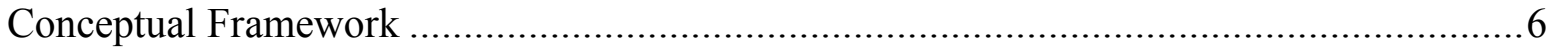

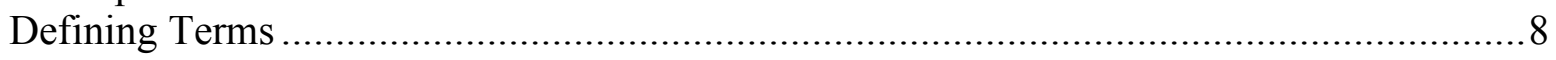

CHAPTER 2

Review of the Literature .....................................................................................................10

Conceptualizations of Racial Difference within Canadian Schools ................................ 10

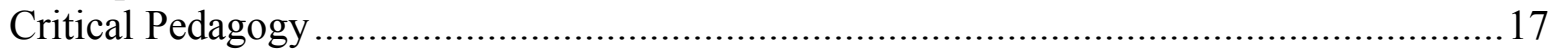

Integrating Critical Pedagogy into the Canadian Education System .............................22

Performative Critical Pedagogy .....................................................................23

Benefits of Performative Critical Pedagogy ....................................................... 24

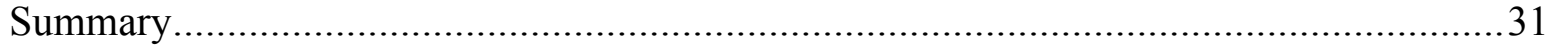

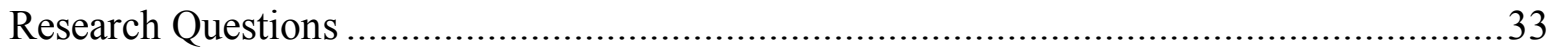

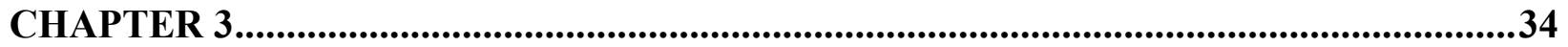

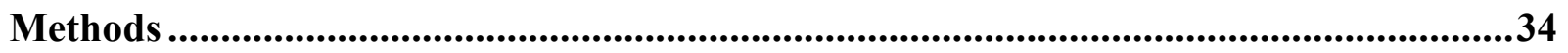

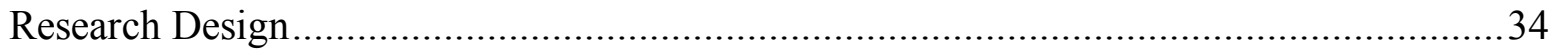

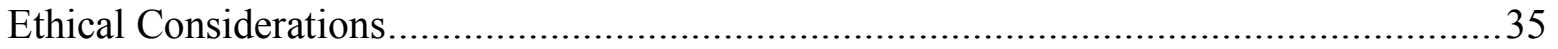

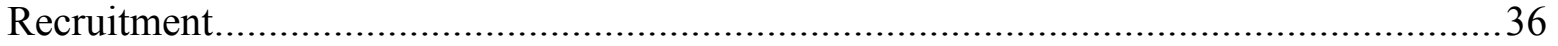

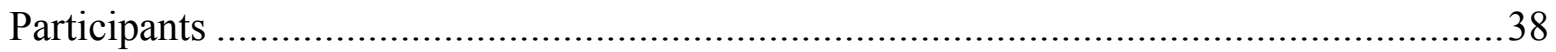

Data Collection ........................................................................................... 40

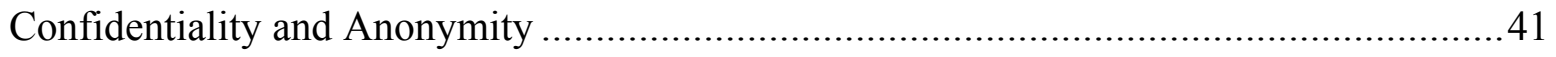

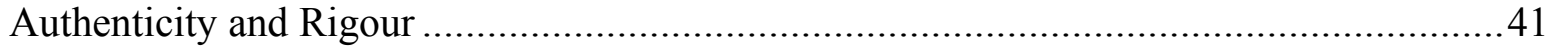

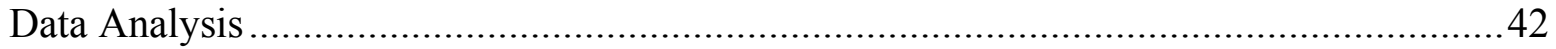

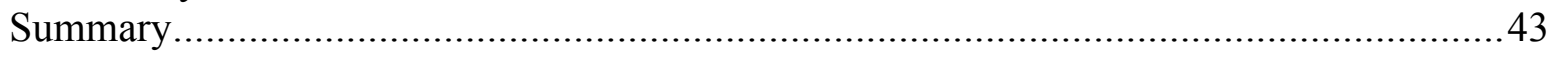

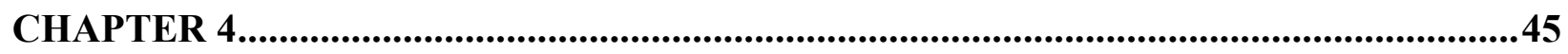

Findings .................................................................................................................................45

Motivating Factors for the Inclusion of Performance-Based Teaching Practices ...............46

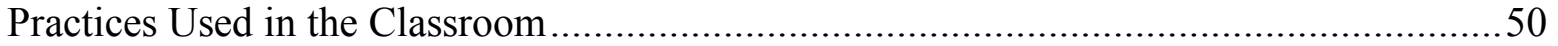

Benefits of Performance-Based Practices with Youth ...............................................5

Challenges Participants Faced ............................................................................. 63

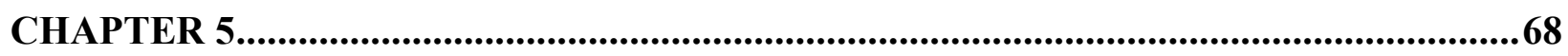

Discussion ..........................................................................................................................68 


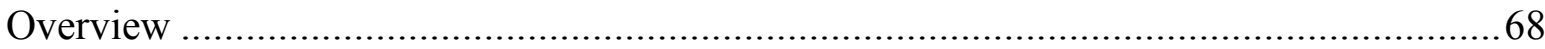

Practices Used in the Classroom ................................................................................ 70

Benefits of Performance-Based Practices with Youth ............................................... 71

Challenges Associated with Implementing Performance-Based Practices in the Classroom73

Feasibility of Implementing Performance-Based Practices..................................... 74

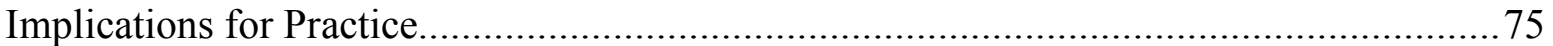

Limitations to the Study and Directions for Further Research ..................................... 77

Appendix A: Email Message........................................................................................78

Appendix B: Email Message for Participant Recruitment from the Council of Ontario Drama and Dance Educators (CODE) .............................................................................79

Appendix C: Email message from Madison Gaudry-Routledge to potential participants ..80

Appendix D: Recruitment Letter .............................................................................................81

Appendix E: Consent Letter ....................................................................................83

Appendix F: Interview Guide................................................................................87

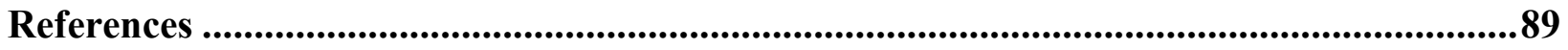




\section{CHAPTER I}

\section{Introduction}

\section{Overview of the Issues}

I grew up in the heart of Toronto, Ontario - a city that prides itself on multiculturalism. But what does this really mean? Multiculturalism is a widely contested topic that can hold a variety of meanings (Ghosh \& Galczynski, 2014). There are those who perceive multiculturalism as the existence of different cultures (ethnic and racial) that are not White (Ghosh \& Galczynski, 2014). This understanding supports traditional European-North American values that situates Whiteness as the 'norm' or default identity and maintains the myth that equal opportunity exists for all individuals regardless of differences. Many interpret multiculturalism as stressing the equality - not equity of all races and cultures, thus erasing difference completely (Ghosh \& Galczynski, 2014). In education, this has often resulted in the teaching of a benign definition of equality and difference, one that ignores power imbalances entirely and instead, celebrates the idea that everyone is equally different and therefore the same (Boler \& Zembylas, 2003; Ghosh \& Galczynski, 2014).

As a White person, I had never experienced what it was like to be racially different. I did, however, acknowledge that I was privileged - not because I was White - but because I felt as though I lived in such a diverse city and country that fostered an equitable environment for all regardless of their identity. I soon came to realize just how blatantly untrue this was. Further, I began to understand just how problematic my learned understanding of difference, privilege and oppression was and how I played an active role in maintaining the status quo.

As Daniel (2016) noted, Canadian society, as we understand it today has many positive attributes. The overall quality of life for most citizens is generally good. We have not had to 
endure many natural disasters, are a reasonably safe country and we currently hold a very diverse population, including many inhabitants who have migrated from various parts of the world (Ash, 2004; Day, 2000; Salojee, 2004; Daniel, 2016). While by no means an exhaustive list, aspects of diversity within Canada include: religion, ethnicity, race, sexuality, gender, ability, and language (Dill \& Zambrana, 2009; Solomon \& Simon, 2011; Ghosh \& Galczynski, 2014; Daniel, 2016). As Daniel (2016) illustrated, "Canada is uniquely positioned to harness and develop the potential of its increasingly diverse population" (p.6). However, Canada has contributed and continues to uphold and normalize oppression, marginalization and other various systemic forms of discrimination and racism (Boler \& Zembylas, 2003; Dei, 2007; Solomon \& Singer, 2011; Carr \& Lund, 2014; Gallagher, 2014; Daniel, 2016). It is therefore necessary to address the disparities, opportunities and challenges currently existing in our society and impeding our ability to embrace a more just and equitable society for everyone (Dei, 2007; Solomon \& Singer, 2011; Carr \& Lund, 2014; Gallagher, 2014; Daniel, 2016).

Over the past 20 years, many Western countries have experienced significant demographic shifts (Ryan, Pollock \& Antonelli, 2009; Daniel, 2016; Duffy \& Powers, 2018). The intersectionality of various identity markers is one of the many factors that have inevitably made contemporary classrooms significantly more diverse and complex (Gallagher, 2014; Duffy \& Powers, 2018). Consequently, the role of a teacher now entails certain demands that greatly exceed traditional requirements, subject matter and teaching models (Duffy \& Powers, 2018). While the diversity of student populations continues to rapidly grow, the proportion of racially, ethnically and linguistically diverse teachers continues to decline (Sleeter, 2001; Howard, 2006; Frideres, 2007; Ryan, Pollock \& Antonelli, 2009; Solomon \& Singer; 2011; Matias \& Mackey; 2016). 
Although there is an abundance of literature that speaks to the composition of Canada's growing diverse population there is considerably less information regarding the distinct make-up of Canada's educators (Frideres, 2007; Ryan, Pollock \& Antonelli, 2009; Solomon \& Singer, 2011). Evidence from other Western societies, such as the United States of America (U.S.A) (Thompson, 2009; Cohn, 2016; Duffy \& Powers, 2018) have indicated that not only is the racialized teacher population substantially disproportionate to its growing diverse student population, it is actually continuing to decrease (National Collaborative on Diversity in the Teaching Force, 2004; Ryan, Pollock, Antonelli, 2009; Solomon \& Singer, 2011). This imbalance between a predominantly White teaching force and a racially diverse and non-native English/French speaking student population has resulted in an isolating divide between nonWhite students and White educators who are not properly prepared to effectively teach racially diverse students (Frideres, 2007; Dei; 2007; 2014a; Solomon \& Singer, 2011; Matias \& Mackey; 2016).

As offered by Gallagher (2014), young people in Canada are currently enduring the effects of growing inequality in a tangible way, which is made evident through their experiences and struggles within the education system. According to UNICEF (2013), Canada now finds itself in an undeniably concerning position, particularly in regards to youth and education. Of particular relevance is the fact that Canada has one of the highest percentages of young people between the ages of 15-19 not participating in education, training, or employment (UNICEF, 2013; Gallagher, 2014). As we consider Canada's legacy of oppression and acknowledge the increasingly diverse nature of our current cosmopolitan society, many teachers, teacher educators and scholars (Duffy, 2010, Solomon \& Singer, 2011; James, 2012; Ghosh \& Galczynski, 2014; Carr \& Lund, 2014; Dei, 2014a; Gallagher, 2014; Daniel, 2016, Matias \& Mackey, 2016) have 
agreed that there has never been a more crucial time for a renewed commitment to equity through the pursuit of critical and anti-oppressive pedagogical approaches.

One of the many challenges facing Canadian educators today is learning and teaching about White racial identity and White privilege (Dei, 2007; 2014b). Discourse on race, difference and anti-oppression often avoid a critical discussion of White identities and privilege, thus reinforcing hegemonic Whiteness (Dei, 2007). As Dei (2007) suggested, "racism can be best addressed when everyone addresses their role in maintaining the status quo" (p. viii). According to Cahnmann-Taylor \& Souto-Manning (2010), "the status quo must change in order to pursue a fully harmonizing pedagogy for all learners" (p.23). Therefore, there is an important entry point for White researchers in the work of anti-oppressive education which is the critical examination of Whiteness and White identity (Dei, 2007).

One way to address this issue of systemic White normativity, as well as pervasive misunderstandings of marginalization and oppression within the Canadian education system is through the incorporation of critical performative pedagogical approaches to the teachings of difference. Having worked at The Second City, a Toronto club famous for sketch and improvised comedy and which often incorporates performances that address identity politics, difference, and injustice, for many years throughout my undergraduate education, I came to understand the power of such performative approaches. Such transgressive performances have the ability to influence behaviour and thus, our cultural attitudes. Theatre, performance-based art, film, television, and music, for example, confront our perceptions every time we engage with them.

\section{Significance of the Study}

Education has a crucial role in both navigating through the challenges and nurturing the potential of diversity (Dei, 2014a). This study aims to explore the pragmatic ways in which 
individuals, particularly youth ages 8-17, are taught within the Canadian education system, specifically Ontario, on topics of racial and social differences, and how this influences their understanding of the construction of identity, and the systemic oppression of marginalized groups. This study positions educators and their unique perspectives and experiences with performance-based teaching as fundamental to providing insight on the teaching and learning process by encouraging teachers to engage and reflect on their own experiences within the education system and how they believe their teachings have influenced their students' understandings of themselves, others and the oppression of marginalized identities.

It is crucial to address and problematize the ways in which racism and discrimination imbues Canadian institutions and shapes culture in order to move towards a model of antioppressive education and, hopefully, towards a more equitable society (Solomon \& Singer, 2011; Dei, 2014a). Such pedagogical frameworks must be action-oriented and aim to directly address racism as well as the inevitable complexities and intersections of difference (such as gender, ethnicity, class, sexuality, ability, language and religion) within the educational system (Dei, 2014a). Further, such educational strategies must seek to acknowledge race and social differences as central to the identities and lived experiences of students as well as the teachers themselves (Cahnmann-Taylor \& Souto-Manning, 2010; Solomon \& Singer, 2011; Dei, 2014a).

This research contributes to the existing discourse in the area of North American education. Particularly, this study examines alternative pedagogical practices aimed at promoting equitable education, education policy and issues of representation, identity and inclusion within the education system. This work does not aim to represent the lived experiences of those who have endured marginalization, rather it attempts to illuminate the complexities of those who try to understand and transform current inequitable realities (Gallagher, 2014). The results from this 
research could support, encourage and empower all those interested in challenging traditional educational paradigms to reflect on alterative pedagogical practices and curricular policies in the collective goal of redefining education for social change and recognizing diversity (Trifonas, 2003; Solomon \& Singer, 2011; Ghosh \& Galczynski, 2014; Dei, 2014b; Daniel, 2016; Matias \& Mackey, 2016).

\section{Conceptual Framework}

This research is framed by critical theoretical perspectives and includes aspects of both critical race theory (Crenshaw, Gotanda, Peller \& Thomas, 1995; Delgado \& Stefancic, 2017), and critical democratic theory (Portelli, 2011; Solomon \& Singer, 2011). It explores how racial differences have predominantly been discussed and taught in the Canadian education system. Further, this work seeks to address how these understandings of difference contribute to the marginalization of racialized students today and the influence this has on their learning capabilities, social and economic opportunities and educational success (James, 2012; Daniel, 2016). A critical democratic perspective values equity, as opposed to equality of opportunity, and acknowledges and respects the intersectional aspects of difference both in theory and practice (Portelli, 2011; Solomon \& Singer, 2011). The inclination to apply these theoretical lenses is based on the premise that categories of social identity, such as race, gender, social class, sexuality and ability, must be understood as social constructions which intersect with each other in ways that influence the degree of privilege or marginalization one will experience based of their specific identity (Crenshaw, 1991; Comeau, 2007; Daniel, 2016).

This study is guided by a critical pedagogical approach that examines how teachers address topics of difference and marginalization with their students through performance-based methods, and raises questions about the significance of these, often unexamined, daily practices 
(Solomon \& Singer, 2011). The incorporation of such methods has proven to be effective in the teachings of difference within an educational setting (Trifonas, 2003; Boler \& Zembylas; 2003; Solomon \& Singer, 2011; Dei, 2014a; Gallagher, 2014; Duffy \& Powers, 2018). This model is premised upon the idea that education should promote students to think analytically, particularly around topics involving social conditions, power, identity and representation (Howard, 2004; Solomon \& Singer, 2011). Notable proponents of critical pedagogy such as Paulo Freire (1970), Henry Giroux $(1997 ; 2011)$, and bell hooks $(1994,2003)$ suggest that students should have an active role in shaping their educational experience and that this is impeded by several social, political, cultural and economic obstacles.

Freire (1970) argued that, "pedagogy which begins with the egotistic interests of the oppressors and makes the oppressed the objects of its humanitarianism, itself maintains and embodies oppression” (p.54). As a White researcher conducting an inquiry on marginalization and racialization processes, it is necessary to contextualize this research through Freire's framework and acknowledge that this research has potential to be problematic even though its objective is to reflect on and deconstruct these issues.

While there are many empirical studies that suggest individual and social change within the education system is possible, rarely do we learn how this change might occur (Howard, 2004; Cahnmann-Taylor \& Souto-Manning, 2010). Performance-based practices can help facilitate the transition between the ideological aspects of critical pedagogy, as espoused by Freire (1970) and praxis in a positive, engaging way (Howard, 2004; Cahnmann-Taylor \& Souto-Manning, 2010).

Grounded in the work of theatrical activist, Augusto Boal's (1979) Theatre of the Oppressed, performance-based pedagogy has long been associated with critical pedagogy and anti-oppressive education as it embodies reflective practices that holds the potential to subvert 
traditional epistemological frameworks of teachers and of teaching through theatre (Duffy \& Powers, 2018). Research suggests that performance-based pedagogical methods have proven to be highly valuable in the area of addressing difference and evoking social change, as they establish a community that educates and empowers participants including both students and educators, which is conducive to critical understanding and fostering a safe, equitable learning environment (Howard, 2004; Cahnmann-Taylor \& Souto-Manning, 2010; Snyder-Young, 2011; Gallagher, 2014; Desai, 2017; Duffy \& Powers, 2018). As Harman and French (2004) offer, the collaborative and action-oriented use of the body within a particular familiar and local context can help students and teachers connect viscerally to topics of racial and cultural difference, identity and oppression. For this reason, this research will explore how performance might be used as an "invitation for the body to join the mind" (p.22) in a critical, transformative approach to learning, teaching and discussion of difference (Cahnmann - Taylor \& Souto - Manning, 2010).

\section{Defining Terms}

White Privilege. White racial identity is about White privilege and the implications this has for both White and non-White individuals (Dei, 2007;2 014). According to Daniel (2016), White privilege "refers to the various benefits that members of society who are racially marked as 'White' receive simply because they possess white skin" (p.20). In a Canadian context, Europeans colonized the land originally occupied by Indigenous populations, and established a racial hierarchy of which they were placed on top and Indigenous groups on the bottom (Daniel, 2016). Europeans attributed social rewards only to those with white skin, as this was the primary marker of racial difference and thus, the determinant factor of entitlement (Jablonski, 2012;

Daniel, 2016). This research focuses on how White privilege has been embedded and maintained 
within the institutions and structures of Canadian society and therefore, still persists today (Lund \& Carr; 2014; Daniel, 2016)

Oppression. For the purpose of this research, it is necessary to acknowledge that oppression and its contemporary forms within a Canadian context, has a history which helps us to understand that certain existing normalized ideals that have been perhaps seen as unchangeable, have been socially constructed and reproduced, sadly with little notice, by humans over time, and therefore can be changed (Solomon \& Singer, 2011; Daniel, 2016). Canada's history of intolerance and oppressive practices is made illustrative through the forced assimilation of Indigenous populations through residential schools (Solomon \& Singer, 2011; Carr \& Lund, 2014). Meritocracy. For the purpose of this research, meritocracy is understood as a myth that is consistently supported and reproduced within the Canadian education system as it negates the fact that certain differences can disproportionately hinder students' abilities to succeed as easily in comparison to non-marginalized students (Boler \& Zembylas, 2003; Dei, 2007; 2014; James, 2012; Daniel, 2016) Further, the Canadian education system often marks the failure of students to succeed academically, or socially exclusively as a result of lack of effort, without taking into account other possible aspects of their lived experiences (Boler \& Zembylas, 2003; James; 2012; Daniel, 2016). 


\section{CHAPTER 2}

\section{Review of the Literature}

The purpose of this literature review is to provide relevant background information on critical pedagogy, performance-based teaching methods, and the benefits and challenges of these approaches within the context of the Canadian education system. Specifically, this analysis will

offer insight on the effects of these alternative practices on students' understandings of diversity, power relations, oppression, as well as their own identities. How racial and cultural difference has been traditionally conceptualized and taught within the Ontario education system will also be addressed. The objective is to develop an understanding of what the research discloses when performance art is examined in the context of a school environment and to determine the association between performance-based teaching and students' appreciation towards issues surrounding power, diversity, themselves and others.

\section{Conceptualizations of Racial Difference within Canadian Schools}

Although independently characterized by distinct historical, social, cultural and political differences, the trajectories of many democratic Western histories share a past marked by colonialism and injustice (Solomon $\&$ Singer, 2011). These power imbalances continue to affect our society’s "social discourse, institutions, and individual consciousness with racism, ethnocentrism, classism, heterosexism, ableism and a variety of other hostile and exclusionary thoughts and practices" (Solomon \& Singer, 2011, p.3). Solomon \& Singer (2011), emphasized the collective need to acknowledge how the inequalities that have shaped our history undeniably continue to be maintained in our everyday lives, written in texts, shown in media and embodied in our subjectivities. 
Daniel (2016) supported this view and stressed the importance of examining the historical roots of various Canadian institutions in order to better understand how power dynamics are established and maintained. She noted that when considering the Canadian education system, it is necessary to address how this institution was initially constructed by European colonizers in such a way as to ensure that their families, and those that looked like them, would continue to benefit from that system. For example, the content and ideas offered in the curriculum, as well as the historical narratives, were set up in such a way to highlight and normalize those in power and portray them as heroic leaders. Traditionally, this curriculum, which has been institutionalized and taught within Canadian schools, has used texts that present imagery of European males as saviors or as professionals, including roles of scientists, professors, engineers, politicians and doctors (Daniel, 2016). These prevalent representations speak to the roots of White normativity within the education system as they identify who is expected to succeed in society, and thus receive social and economic benefits, and who is excluded from these positions of power and leadership (Doxtator, 2011; Daniel, 2016).

Education and The Myth of Meritocracy. Education has long been understood as an integral component of a functioning Canadian democratic society, as it supposedly serves as an equalizer for all students by conveying objective knowledge of our world, including our social and political institutions (Ghosh \& Galczynski, 2014; Daniel, 2016). The central idea being that if an individual has access to an adequate education, they will then be able to succeed in all other areas of their life. This ideology is widely supported throughout every facet of Western social, cultural and political practice resulting in the production and normalization of meritocracy (Daniel, 2016). 
The education system, specifically, has long functioned as a vehicle for the reproduction of problematic cultural myths and ideologies, such as the myth of meritocracy and individual liberalism, as it is often thought of as a tool that can either help students achieve success or meet their failure depending upon how one chooses to engage with the system and how much effort one puts into their experience at school (Boler \& Zembylas, 2003; Daniel, 2016). Within this ideological framework difference is not considered a factor that could impede one's ability to achieve success (Boler \& Zembylas, 2003; Daniel, 2016). According to the myth of meritocracy, privileges and inequalities emerge as result of individual effort and differences are often either disregarded, tolerated or celebrated as a part of a benign conceptualization of multiculturalism (Boler \& Zembylas, 2003; Ghosh \& Galczynski, 2014; Daniel, 2016).

In their work on difference, critical inquiry and alternative pedagogical methods, Boler and Zembylas (2003), examined how the myth of meritocracy and individual liberalism are integrated and upheld throughout dominant discourse within the Western education system. They proposed that such notions greatly depended on the acceptance of multiple reductive understandings of difference and outlined predominant models of addressing difference in the classroom. An example of this is the "denial/sameness model," (p.110) which erased individual difference and negated systemic oppression while promoting assimilation. Additionally, the “natural response/ biological model," (p.110) maintained that some differences are inherent based on biology and that it is a natural human response to fear those who are different, thereby allowing those in power to rationalize their discriminatory and oppressive practices towards other groups (Boler \& Zembylas, 2003).

A common variable amongst these approaches is the failure to acknowledge how differences are perpetually constructed and sustained through social and institutional levels 
(Boler \& Zembylas, 2003; Comeau, 2007; Ghosh \& Galczynski, 2014). Further, there is a collective unwillingness to engage in the challenging work of critical self-reflection and the reconstruction of one's own views and assumptions (Boler \& Zembylas, 2003; Ghosh \& Galczynski, 2014).

White Normativity and the Canadian Education System. In his own work in Canadian schools, anti-racism and anti-oppression, Dei $(2007 ; 2014 \mathrm{a})$ has emphasized the complex politics and widespread denial of race and difference, even as racism and discrimination present themselves as operative, living issues within Canadian society. As Dei (2014a) argued "race powerfully implicates and orients schooling, and any education that sweeps race under the carpet is a miseducation of the learner" (p. 240). Although racialized/ minoritized students continue to express their anxieties about prejudice and racism, many others meet these concerns with denial and silence, not to merely protect their own privilege, but to rid themselves of any responsibility in enabling social oppression (Dei, 2007). While there are many who are actively involved in attempting to make for a more positive, equitable learning environment it is important to recognize those, namely White people, who maintain the power and privilege to detach themselves from those who are most directly marginalized by racism (Dei, 2007, Matias \& Mackey, 2016). Unfortunately, even in instances where educators do attempt to challenge these notions of difference they are often met with considerable resistance from colleagues and administrators for example (Boler \& Zembylas, 2003; Solomon \& Singer, 2011). As Boler and Zembylas (2003) offered, engaging students and educators in critical analysis of difference requires the deconstruction of education neutrality and dominant cultural myths.

Ghosh and Galczynski (2014), and Comeau (2007), agreed with Boler \& Zembylas (2003) about the need to challenge the notion that education is objective and, instead, speak to 
the ways in which cultural difference is problematized and reproduced through racializing discourse within the Canadian education system. Although there have been multicultural education programs put in place aimed at promoting social justice for racially and culturally diverse students, considering that inequalities still persist for certain groups, these initiatives have been generally unsuccessful in creating substantial change (Ghosh \& Galczynski, 2014).

As Comeau (2007) argued, the lack of success surrounding social justice initiatives within the Canadian education system is largely due to the fact that current educational discourses that are considered progressive often offer information about racialized groups in a way that appears sympathetic yet is still complicit in reinforcing White racial dominance through the making of a racialized "Other" (p.46). It is this apparent sympathetic quality that distinguishes this 'knowledge' from blatant discriminatory understandings of marginalized groups, which suggests that the sympathetic knower is tolerable and therefore incapable of racism. One could argue that the power relations between White people and racialized groups continue to be reflective of colonial power relations from a century ago, as the dominant group maintains the ability to define what the problems are, who creates these problems, and what the possible solutions might be (Comeau, 2007).

The Construction of Racialized Students as the Problem. Various studies (Bourdieu \& Passeron, 1977; Solomon \& Singer, 2011; James, 2012; Ghosh \& Galczynski, 2014; Daniel, 2016) have indicated that the presence of unequal power relations within the school environment has contributed to the ways in which students of different backgrounds construct and understand their own identities as well as the identities of others. The failure to properly address power relations within the Canadian education system and the ongoing tendency to attribute the problem of social inequality as inherent within the identity of the 'Other' has resulted in the 
maintaining and reproduction of dominant societal power imbalances (Comeau, 2007; Dei, 2007; James, 2012; Ghosh \& Galczynski, 2014).

In his work on equitable education, James (2012) examined how stereotypes and other forms of racist discourse contributed to the social construction of African Canadians as "at risk" (p.464) students. The disengagement and low academic performance of Black male students has long been a concern for parents, educators and youth in Canadian schools (Abdada \& Lin, 2011; Caldas, Bernier, \& Marceau, 2009; Codjoe, 2006; James, 2009; 2012). As a consequence, these students are often labeled as 'at risk' who require special educational assistance (James, 2012).

Levin (2004) defined an 'at risk' student as “one whose past and present characteristics or conditions are associated with a higher risk or probability of failing to obtain desired life outcomes" (p.2). However, as James (2012) pointed out, the 'at risk' classification tends to be less about the specific learning needs of these students and more often about the disparities that contribute to their lack of educational engagement.

James (2012) drew on the research of Wotherspoon and Schissel (2001) in his discussion of 'at risk' discourse. Specifically, he highlighted how using this term is imbued with racism, sexism and other discriminatory ideology based on a variety of elements that are perceived to contribute to an 'at risk' status. These factors include: neighborhood, immigration status, stereotypes and socioeconomic class. While he recognized that there may be a need for schools to identify students who are failing to attend class or earn a passing grade, there is little evidence demonstrating that such interventions aimed at helping youth are having a positive effect on these students, particularly African Canadian males.

As James (2012) concluded, racialized students continue to be considered the most 'at risk' due to the fact that Canada's education system is informed by a conception of 'colour- 
blind' multiculturalism, which consistently disregards/ fails to acknowledge the influence that race and racism have on students' experiences within the school. He suggested that what is needed for Canada's education system is not disciplinary action for students, or rigid evaluation measures, but rather a differentiated approach to students' learning that addresses their specific needs by acknowledging and striving to understand their lived experiences and subjectivity.

In her study in Saskatchewan, Canada, Comeau (2007) examined how White educators developed their sense of awareness through discussing their experiences working with racialized students. These educators worked predominantly with Indigenous students, and also selfidentified as being committed to social and racial justice through their teaching. She discovered that despite whether or not racial and cultural differences were discussed in positive or negative ways, central to these participants was their mutual tendency to describe Indigenous people as inherently problematic thus, locating "the problem" (p.58) of social inequality as intrinsic within the differences of certain groups of people (Comeau, 2007). The used flawed logic here being, if there are no differences, there are no problems.

As Comeau (2007) proposed, what is needed to properly address current inequitable power relations is to first identify and dismantle the essentializing of categories of race and culture. Secondly, it is necessary to disrupt the idea that 'the problem' of social inequality is inherently contained within the racialized 'Other' and instead, focus on how 'the problem' lies in the construction of dominance and maintenance of White superiority. Further, she emphasized the importance of the education system in identifying the legacy of White supremacy as well as problematizing the interest of White people in upholding power, privilege and a sense of exemption in the maintenance of racial injustices. 
Ghosh \& Galczynski (2014) further supported the work of Comeau (2007) and James (2012) noting that instead of focusing solely on diverse ethnic cultural groups, it is necessary to examine the "politics of difference" (p.8) as the education system involves negotiating the relationship between cultural ideals and power relations. The politics of difference addresses the power imbalance that occurs when racialized students or students of difference are measured against ideals and norms established by the dominant group (Ghosh \& Galczynski, 2014). Therefore, as Ghosh \& Galczynski (2014) argued, the education system must be inclusive and strive to develop an environment in which difference is not considered negative. Further, discussions of social inequality must address the power relations between dominant groups and marginalized groups while ensuring that explanations of social inequality do not suggest that 'the problem' is inherent within the marginalized identity, but rather that the problem lies in the dominant group's vested interest to maintain power (Comeau, 2007; Ghosh \& Galczynski, 2014).

\section{Critical Pedagogy}

Scholars and proponents of critical pedagogy share many commonalities in their theories and deployments of this approach while also offering their own nuances to it as outlined by Paulo Freire (1970; 1997; 1998), bell hooks (1994; 2003), Henry Giroux (1997; 2011), Cahnmann-Taylor (2006; 2010); Souto-Manning (2009; 2010) and Tracy Davis and Laura Harrison (2013). Specific to this research is the way in which critical pedagogy has been integrated into the Canadian education system and looks to the work of Canadian scholars and educators, Solomon and Singer (2011) and Daniel (2016), who ground their research and teaching practices within the critical pedagogy paradigm and have long been working towards 
the development and implementation of equitable education practices and social justice for marginalized groups.

Freire's (1970) conceptualization of critical pedagogy rejected the top-down model of education where power is centralized and instead, served as an alternative method of teaching in order to subvert the status quo and liberate all learners. His work exposed and problematized what he referred to as the "banking education" (p.53) model, whereby teachers merely transfer knowledge to students who passively accept this knowledge as fact. He suggested that such educational processes, which fail to acknowledge education and knowledge as a process of inquiry, can have many negative consequences for students and society such as weakened democratic participation. Instead, he offered an educational approach that focused on identifying and discussing the specific concerns and struggles of students.

According to Freire (1970) liberation is determined by one's ability to transform their reality and requires what he referred to as "praxis" (p.102) also understood as conscious action (Davis \& Freire, 1981). Freire's (in Davis \& Freire, 1981) critical pedagogy therefore centered on the key concept of praxis where educators and learners engage in the construction of knowledge together. This process enables them to become self-reflective individuals and develop the ability to critically examine and actively transform reality.

Freire (1970) offered two main approaches to developing praxis: problem posing and dialogue. Problem-posing is the process of students and teachers asking questions surrounding the world in which they inhabit, including their lived day-to-day realities, and critically examining the possible actions they may take in order to transform current circumstances (Shor \& Freire, 1987). In applying this teaching philosophy educators base their inquiry off of the lived 
experiences, knowledge and concerns of their students (Cahnmann-Taylor \& Souto-Manning, 2010).

To initiate problem-posing in a functional sense and engage students in dialogue requires teachers to become immersed in the communities of their students in order to develop an understanding of their realities and pervasive struggles (Cahnmann-Taylor \& Souto-Manning, 2010). Using an ethnographic approach, educators then collect data and codify the prevalent and applicable themes (Freire; 1970; Shor, 1992; Cahnmann-Taylor \& Souto-Manning, 2010). Through dialogue and critical analysis, "generative themes" (p.86) are created, representing students' lived realities (Freire, 1970).

Dialogue is understood by Freire (1970) as a necessary part of the development of human consciousness. He noted, "dialogue is a moment where humans meet to reflect on the reality as they make and remake it" (Shor \& Freire, 1987, p.98). Through dialogue, human beings can form an understanding of what they know, as well as what they do not know. Self-reflection identifies how current knowledge is limited and how it can be enhanced, thus strengthening the capacity to transform oppressive aspects of reality (Shor \& Freire, 1987).

One example to illustrate the ways in which praxis is developed in the classroom setting through problem-posing and dialogue is Cahnmann- Taylor's (2006) ethnographic study of a Nicaraguan-born teacher and her multi-age Puerto Rican students in North America. In this exploration, critical pedagogy was applied through the use of generative themes that directly reflected students' lived realities, such as national and local discussions involving bilingual education and the disputed sovereignty of the island of Vieques, Puerto Rico, which was occupied by the U.S. military. Generative themes emerging through praxis empowered the students through active experience. 
hooks (1994; 2003) agreed with and expanded Freire's (1970) conceptualization of critical pedagogy being an active experience. The significance of education as a practice of freedom influenced her work in the field of anti-oppressive education and enabled her to challenge the "banking system of education. Central to hooks' teaching approach is critical awareness and the belief that it is necessary for herself and all of her students to be active participants in the construction of knowledge and learning process, as opposed to passive consumers.

Specific to hooks' $(1994 ; 2003)$ critical pedagogy is the concept of an engaged pedagogy which she suggested is more rigorous than the conventional use as it stresses the significance of well-being. This means that educators must actively work towards maintaining their own personal contentment through a committed engagement in a process of self-actualization in order for them to effectively teach students in an empowering manner (hooks, 1994). hooks (1994; 2003) draws on the work of Buddhist monk and social rights activist, Thich Nhat Hanh (as cited in hooks, 1994). Like Freire (1970), Hanh (as cited in hooks, 1994) made the connection between consciousness and practice. However, while Freire (1970) was more focused on the power of the mind Hanh (1987) stressed the importance of wholeness that connected mind, body and spirit.

Similar to Freire (1970) and hooks (1994; 2003), Giroux’s (1997; 2011) work in critical education was motivated by the emergence of the authoritarian politics in the American education system. He advocated for the importance of active participation in the construction of knowledge and encouraged students to critically engage with texts rather than consume them passively. Building on the work of Freire (1970), Giroux $(1997 ; 2011)$ viewed critical pedagogy 
as an approach that centered on restoring freedom and reason in instances where social agency had been denied.

Rooted in critical theory and building off of Freire's (1970) foundational work on antioppressive education, The Pedagogy of the Oppressed, Davis and Harrison's (2013), conceptualization of critical pedagogy centered on the perspectives of marginalized students. Their contemporary work on critical pedagogy involved exploring the various ways in which knowledge is socially constructed, highlighting the sociohistorical and economic factors that shape knowledge. These include, revealing the ways in which information becomes legitimized, focusing on the subjectivity of the learner, in which their lived experience as the knower informs learning strategies and promoting participation in the construction of knowledge (Davis \& Harrison, 2013).

Davis \& Harrison (2013) defined social justice action as efforts to ensure that the lived reality of many individuals is reflective of the rights and freedoms outlined in governing official documents, like the U.S constitution and the Canadian Charter of Rights and Freedoms. They suggested critical pedagogy was a conducive framework for effecting social justice and change due to its "recursive, context-illuminating, and dialectic demands" (p.84). Meaning, critical pedagogy is a necessary method in challenging hidden hegemonies and assimilative practices, through a strategic framework that critically examines decisions, policies and common procedures that are not typically analyzed or questioned. Specifically, the dialectic nature aims to address the nuances among significant concepts as well as examine the various ways in which knowledge is formed. As Kincheloe (2005) states, dialectical education "seeks to free knowledge production from the authoritarian explanations of the certified experts" (p.23). This then 
emphasized participation and rejected the notion that learners should be mere passive recipients of the knowledge production process (Davis \& Harrison, 2013).

\section{Integrating Critical Pedagogy into the Canadian Education System}

In considering the scope of Canada's deep-rooted inequalities and what action needs to be taken in dismantling this cycle, Solomon \& Singer (2011) suggested that there must be a transformation of the structural and systemic nature of societal inequities, as well as a shift in the constructed perceptions of individuals. Their research explored how progressive teachers responded to the conservative and assimilative education reform by documenting the experiences of teachers who graduated from the Urban Diversity Teacher Education (UD) Program at York University, Toronto, Canada.

Rooted in a social reconstructionist philosophy and guided by Freire's (1970) notion of praxis, the UD program seeks to develop "conscientization," (p.36) which emphasizes the importance of acknowledging one's own responsibility in addressing and resisting oppressive aspects in one's life or the lives of others, amongst teacher candidate graduates (Solomon \& Singer, 2011). The main objective of developing the UD program was to assist preservice teachers in developing their pedagogical perspectives and aimed to integrate issues of diversity, equitable teaching practices and inclusive understandings of social justice into all aspects of the program including theory, experience and practice (Solomon \& Singer, 2011).

Daniel's work (2016) supported Solomon's and Singer's (2011) research. She shared firsthand how the preparation of teachers continuously overlooked the significance of inclusion, social justice and anti-oppressive discourse and practices. Through her experiences teaching in a Canadian context, she not only observed the current underrepresentation of racialized students within the curriculum and faculty, but also engaged with students who attested to the differential 
treatment they experienced based on their race per teachers who were insufficiently trained, and therefore unable, to address the various needs of their increasingly diverse classrooms. Daniel's (2016) anecdotes highlight the importance of recognizing how the differential treatment of racialized groups is entrenched within Canadian society in ways that appear invisible.

\section{Performative Critical Pedagogy}

According to Gallagher (2014), there has been a continuous effort to focus on the importance of student voice and perspective in education scholarship. The contexts and practices that have proven to be most conducive in highlighting student voices are spaces where young people and adults can collaborate in order to re-imagine and transform the conditions of their own realties and learning (Fels \& Belliveau, 2008; Duffy, 2010; Gallagher, 2014; Duffy \& Powers, 2018). Like many other Western democracies, the social and political conditions of Canadian teachers have been largely impacted by recent educational reforms and restructuring that favour a standardized curriculum and testing, and negate the value of equity-based schooling. (Solomon \& Singer, 2011). Given the context of the current Canadian educational landscape, where those committed to social justice are pitted against the rigid, standards-based curricula, there have been several studies that suggest that a main focus of teacher preparation must be critical self-reflection (Boler \& Zembylas, 2003; Cahnmann-Taylor \& Souto-Manning, 2010; Solomon \& Singer, 2011; Stovall, 2013; Desai, 2017). The objective, then, is to determine how to best encourage critical self-reflection among preservice [and in-service] teachers in order

for them to become aware of their own subjectivity, positions of power, and biases, and how this might translate into enabling the same critical awareness amongst students (Lipman, 2011; Gallagher, 2014; Desai, 2017; Power \& Duffy, 2018). 
Cahnmann-Taylor and Souto-Manning (2010) and Desai (2017) noted that teacher educators have a responsibility to address the various kinds of conflicts that may arise in diverse classrooms, such as, conflicting educational paradigms, racism, sexism, homophobia, and the complex lived experiences of marginalized students and the personal characteristics that come with that reality. Additionally, they suggested it is necessary to consider the best way to prepare these teachers to become competent in engaging with growing diversity in modern classrooms. Although there have been numerous approaches to anti-oppressive foundational learning in teacher education programs, this has predominantly been done through the inclusion of texts that highlight the visible and hidden forms of systemic discrimination (Cahnmann-Taylor \& SoutoManning, 2010). While this is certainly a necessary component to anti-oppressive learning, many studies (Howard, 2004; Conrad; 2004, 2005; Fels \& Belliveau, 2008; Cahnmann-Taylor \& Souto-Manning, 2010; Schaedler, 2010; Snyder-Young, 2011; Gallagher, 2014; Desai, 2017, Duffy \& Powers, 2018) have found that teachers often require more than readings in order to affect substantive change in their lives and those of their students.

\section{Benefits of Performative Critical Pedagogy}

Various studies have noted the feasibility and success of integrating performance-based methods into elementary, middle-school and high-school curriculums, particularly when addressing issues of power imbalance and oppression (Howard, 2004; Conrad, 2004; Duffy, 2010; Cahnmann-Taylor \& Souto-Manning, 2010; Schaedler, 2010; Snyder-Young, 2011; Gallagher; 2014; Desai, 2017; Duffy \& Powers, 2018). Cahnmann-Taylor \& Souto-Manning (2010) suggested that drama and performance-based art are highly valuable methods in the process of developing critical, anti-oppressive learning environments. These practical approaches 
help individuals recognize how their actions, behaviour and performance of self has the potential to either perpetuate or change social conditions.

While the phrase "acting up" (p.4) is often attributed to students who are disruptive, Cahnmann-Taylor and Souto-Manning (2010) offered that these moments of 'bad kid' interruptions should be rethought as "expressions of agentive voice" (p. 4). They propose the idea of 'acting up' as a way to resist structured forms of institutionalized marginalization and promote social change. Their conceptualization of performance-based teaching integrated Freire's (1970) emancipatory, problem-posing, critical pedagogy with the work of theatrical activist, Augusto Boal (1979) and his most notable text, Theatre of the Oppressed (TO) (Cahnmann-Taylor \& Souto-Manning, 2010).

Boal's TO methodology was created with the purpose of providing people with an alternative language and the practical means to address and resist the various forms of oppression they experienced within their daily lives and systemically within society (Howard, 2004; Duffy, 2010; Desai, 2017). Boal's TO aimed to resolve the social and political problems hindering marginalized communities and allowed multiple perspectives to be acknowledged and examined in the process (Duffy, 2010; Desai, 2017).

In $\mathrm{TO}$, critical dialogue is initiated and brought to the forefront through various improvisational games (Schaedler, 2010; Snyder-Young, 2011; Desai, 2017). This playful, engaging environment enables participants to analyze and discuss their lived experiences and subjectivities as a collective (Desai, 2017). Through sharing their lived realities, participants can better identify the causes of oppression, while also transforming their situation by imagining different realities (Desai, 2017). Boal (1979) believed that all individuals needed to be involved in this process since they are all active observers or what he refers to as "spect-actors" (p.6). 
In Cahnmann-Taylor and Souto-Manning's (2010) study with teacher-educators, Boal's (1979) work was adapted to develop meaningful practices to support novice teachers, particularly those of colour or for whom English is not a first language. Instead of simply discussing the various struggles these teachers faced, Boal's (1979) idea of 'spect-actors' was adopted. All participating educators in this exercise became 'spect-actors' listening to each other's experiences and discussing how they related to universal issues surrounding education for social change (Cahnmann - Taylor \& Souto-Manning, 2010). Participants each had the opportunity to portray the protagonist, bilingual teacher who had experienced mistreatment by colleagues and administrators who made discriminatory remarks about these teachers' Spanishaccented English and generally made their daily work day experiences uncomfortable (Cahnmann-Taylor \& Souto-Manning, 2010). Through 'acting up' as themselves in this exercise, the teachers engaged in Freire's (1970) notion of conscientization, where they became conscious of their own subjectivities; the ways in which they, too, had the ability to become antagonists to others, and how their behaviors and words could either reinforce existing inequitable power relations or challenge them (Cahnmann-Taylor \& Souto-Manning, 2010).

Throughout the years, Cahnmann-Taylor and Souto-Manning (2010) have practiced these performative strategies with students of early childhood education, TESOL (Teaching English to Speakers of Other Languages) classes, with College of Education faculty, and in various other contexts from conference workshops, to college seminars and K-12 classrooms. Their work illuminated how performance can be used to transform oppressive situations into meaningful and reflexive learning experiences. Further, they not only acknowledged that change is possible but they demonstrated how change can take place through physical and imaginative modalities (Cahnmann-Taylor \& Souto-Manning, 2010). 
Similar to Cahnmann-Taylor and Souto-Manning (2010), Desai (2017), a teacher educator, conducted a qualitative ethnographic study, where she examined how several preservice teachers in a small, liberal arts, Catholic college in the Southern region of the U.S.A., responded to topics of immigration in their elementary and high school classrooms. Incorporating Boal's (1979) TO, she cultivated a safe learning environment and promoted equitable educational practices aimed at helping these teachers become prepared for dealing with diverse classrooms in a positive and effective way. "By employing TO, participants can better examine root causes, systems of oppression, and develop solutions that address the oppression at a personal and institutional level" (Desai, 2017, p. 231). Most importantly, she noted that the playful and light-heartened nature of TO allowed her to address challenging topics with her class in ways that appeared less threatening while simultaneously highlighting the importance of the issues.

Specific to her approach was the use of Forum Theatre, where narratives of oppression or a particular issue is improvised multiple times by participants (Desai, 2017). As a result, what began as an experiment in order to provide alternative methods for addressing different classroom situations and conflicts turned into a transformative learning experience which allowed pre-service teachers to critically examine their own ontological and epistemological assumptions and how it influenced their teaching (Desai, 2017).

While there is an abundance of material on TO, there is considerably less literature regarding the practice of $\mathrm{TO}$, and performance-based practices in general, with youth specifically, as Boal's primary interest was his work with adults (Duffy \& Vettraino, 2010). Guiding Duffy and Vettraino's (2010) research and performative pedagogical approach is the acknowledgement of the complicated and at times, inconceivable, experiences and lived realities 
of youth. Duffy and Vettraino (2010) are determined to assist those enduring oppressive situations.

In Duffy's (2010) interview with artistic and education director, Chris Vine, who has conducted many TO workshops with youth all around the world, it was revealed that TO was oftentimes not the first method to come to mind when working with younger students and that it was necessary to always consider other related and interactive performative approaches. However, it was offered that there are many key instances in which TO is most appropriate such as situations where individuals are being manipulated or silenced, and in which there are unequal power dynamics between those with power and those who seem to have little or none (Duffy, 2010).

Duffy (2010) has long incorporated performance-based learning practices with his middle school and high school students, specifically through Boal's TO method of Forum Theatre and 'spect-actors.' His work highlighted and depicted the various ways in which power manifests in individual behaviour as well as social institutions, and how different groups are in turn affected by power imbalances. Fundamental to Duffy's (2010) teaching approach was conveying power dynamics that are not solely word driven by "talking heads" (p.191). Meaning, he was concerned with the ways in which messages surrounding power and oppression can be conveyed through modalities other than speech, as people are more likely to develop a deeper understanding of power imbalances when they are able to see these dynamics unfold in front of them. As Vine (as cited in Duffy, 2010, p.193) offered, "you can show the power structures very clearly through images, through movement patterns and spatial relationships that don't rely on word."

Duffy (2010) suggested that the inclusion of the physical forms of performance, such as dance, can be highly valuable in Forum Theatre, as it works to inject physical images within the 
work. Duffy (2010) suggested that this kind of physicality highlights the central messages of the subject matter, which is particularly useful for young people, as they are very responsive to images. Further, Duffy's (2010) performance-based practices encourage young people to identify instances of oppression they experience or notice in their world and provides them with the opportunity to develop an action plan for their futures.

Similar to Duffy (2010), Gallagher (2014) was interested in the ways in which performance-based practices could be integrated within the learning environment and how these approaches impacted the lives of Canadian youth. Gallagher's (2014) ethnographic study with marginalized youth in Ontario, Canada used theatre and storytelling as a pedagogical practice and methodological tool to examine the engagement of high school students. Her main objective was to develop an understanding of why students were engaged or not engaged in the classroom, and how to possibly address these students' needs. Storytelling was implemented as a foundation for inquiry and exploration, where students had the opportunity share their perspectives, experiences and discuss topics or concerns that directly relate to their lives.

As she observed in various Ontario drama high school classrooms, efforts to understand social difference and oppression commonly emerged through the creative and performative works of students, particularly through the use of play building, monologues and digital storytelling projects. Her study addressed the tensions surrounding theatre as an art versus a method of education and the various ways in which drama teachers negotiate these ideals on a daily basis. Gallagher (2014) offered that although some drama teachers are more inclined to focus on the aesthetics of a performance piece, while others are more overtly concerned with the social aspects and well-being of their students, both pedagogies provide an outlet for student's 
personal exploration and open dialogue that subverts traditional learning experiences and knowledge.

\section{Challenges Associated with Performance Based Practices}

While there has been a substantial number of studies that have illustrated the ways in which performative arts-based teaching methods are conducive to the cognitive and affective development of learners (Howard, 2004; Giard, 2005; Fels \& Belliveau, 2008; Cahnmann-Taylor \& Souto-Manning, 2010; Schaedler; 2010; Snyder \& Young, 2011; Gallagher, 2014; Desai; 2017), there have unfortunately also been several studies (Lang, 1999; Conrad, 2004; Fels \& Belliveau, 2008; Cahnmann-Taylor \& Souto-Manning, 2010; Snyder-Young, 2011), which indicate that only a limited number of teachers actually integrate performance-based practices into their teaching due to lack of resources, lack of time, lack of proper training and disinterested students and teachers.

Conrad's (2004) Popular Theatre study also addressed the various obstacles associated with integrating performance-based teaching methods in the classroom. Through her use of Boal's (1979) Forum Theatre, Conrad (2004) embarked on a participatory, performative inquiry into the lives and personal experiences of two mixed grade ten, eleven, and twelve drama classes made up of Indigenous students from rural Alberta. She expressed that teenage students, are often more focused on their relationships with other students in the class and do not necessarily want to discuss larger societal issues (Conrad, 2004). As she stated, "I am skeptical of the extent to which any significant new awareness based on our work carried into the participants' lives" (Conrad, 2004, p.102). However, she suggested that the evaluation of this kind of work is problematic in that the effects of this work are seldom immediate, observable or easily expressed (Conrad, 2004). 
Snyder-Young's (2011) applied theatre study, supported Cahnmann-Taylor and SoutoManning's (2010) and Schaedler's (2010) work. However, she also highlighted some of the more challenging aspects of incorporating these approaches within a classroom. In particular, she addressed some of the more difficult aspects of trying to engage in social-justice discourse with young students. In her 12-week long study, she co-facilitated the drama classroom of an urban charter school in the U.S.A., where 8 young students, of primarily African American and Latin American descent, shared difficult experiences in their lives through the form of scripted and staged scenes and performed several Forum interventions. Snyder-Young (2011) also described her fears of interjecting during what she considered to be off-topic discourse during the process. She felt it would centralize her privileged position, as a middle-class White woman, and serve to colonize the workshop and showcase only her perspective (Snyder-Young, 2011). Her study revealed that while TO is typically aligned with supporting socially progressive perspectives, participants may have a different agenda that does not necessarily orient towards social justice or the agenda of the educator (Snyder-Young, 2011).

\section{Summary}

The intention of this literature review is to form a foundational background of how racial and cultural difference is conceptualized and addressed within the context of the Ontario education system and how various applications of performative critical pedagogy have been used by modern social-justice oriented leaders to help develop a more equitable and inclusive educational environment. The literature suggests that the majority of the research surrounding the effects of performance-based teaching methods has been conducted on adult pre-service teachers, adult students, and adolescents (Conrad, 2004; Fels \& Belliveau, 2008; CahnmannTaylor \& Souto-Manning, 2010; Snyder-Young, 2010, Schaedler, 2011; Solomon \& Singer; 
2011; Daniel, 2016; Desai; 2017). Many of these studies, were conducted with participants who were in the targeted age range of between grade four and grade twelve and between eight and seventeen years of age (Conrad, 2004; Fels \& Belliveau, 2008; Cahnmann-Taylor \& SoutoManning, 2010; Snyder-Young, 2010, Schaedler, 2011).

Despite current policies and institutional spaces that offer support and implement change that are supported by law, discriminatory and assimilative practices continue to be a common daily occurrence for many (Solomon \& Singer, 2011). Policy changes also occur with a new government. For instance, during the course of this research project, there was a change in the government in the province of Ontario. Under the new leadership of Premier Doug Ford and the new 2018 provincial government of Ontario, there is potential upheaval with the impeding regressive changes to some of the current curriculum (for e.g., Indigenous education and Health and Physical education) that addressed inequities. This action creates turmoil and speaks to the volatile nature of the current educational landscape and the politics that occur. The importance of this kind of research is further emphasized though this example. Therefore, while the previous Ontario Ministry of Education (2017) under the leadership of Premier Kathleen Wynne continued to renew their goals for equitable education, it is evident that there is far more research, and work to be done in order to facilitate change within individual, social and institutional inequities. This has led to the following research questions that have framed this inquiry. 


\section{Research Questions}

- How is racial, cultural and social difference predominantly conceptualized within the education system and what are the potential implications of this for students and educators alike?

- How can performance be utilized as a critical pedagogical method in the teachings of difference? 


\section{CHAPTER 3}

\section{Methods}

\section{Research Design}

This qualitative descriptive research design incorporated critical ethnographic methods and used a thematic analysis approach (Creswell, 2014). The researcher is the main tool in collecting data through semi-structured interviews (Creswell, 2014). As Grbich (2013) explained, qualitative research embodies necessary characteristics, such as power primarily attributed to the researched. A holistic approach asserts validity and that the views of the participants, and myself are acknowledged and respected. Further, a qualitative research design is valuable in highlighting the significance of the nuanced experiences and perspectives held by various individuals and addressing how one's own subjectivity can influence their understanding of a particular topic (Gribich, 2013). Gribich (2013) noted that critical ethnography is best suited for research questions that involve how group identity is constructed and represented by dominant cultural institutions such as gender, race, the economy and politics, and whose agenda this ultimately serves.

This research used structured, and tactical sampling in order to obtain data from experienced teachers that would be able to provide enough information to suitably address the research questions (Sandelowski, 2000). The research questions were explored through the use of individual semi-structured interviews and field notes in order to gain first hand insight of teachers' experiences using performance-based methods in their classrooms. The use of interviews enabled unique narratives to be told, providing the possibility to uncover and address alternative knowledges that otherwise may not be recognized (Olson, 2011). These interviews and field notes created the data set used for analysis. 
The data collected for this study was analyzed through the use of themes that emerged in order to best represent the information. A thematic analysis approach was used as it enabled the descriptive data to be represented in a transparent way that draws direct connections to the research question (Braun \& Clarke, 2006; Gribich, 2013). A thematic analysis in a critical ethnographic study allows the researcher to examine various aspects that they originally may not have considered central to the research question (Gribich, 2013). As Gribich (2013) explained, once the original data collection is complete, thematic analysis can be used to group aspects of the data together in order for the researcher to better identify certain themes or instances of power. In order to keep the data largely intact and make the content more manageable, a block and file approach was used in order to group relevant data in broad categories (Gribich, 2013).

The implementation of this kind of analysis, allowed me to effectively summarize the data and represent the information as accurately and authentically as possible to the voice of each teacher who participated and ultimately, allowed for the opportunity to provide insight into teachers' experiences of integrating performance-based methods with youth in a classroom setting (Sandelowski, 2000; Gribich, 2013) Further, these summaries, organized into themes, allowed me to develop explanations of meaning through theoretical concepts, linking systems of power and subordination in order to provide answers to the research question which concerns racial, social and cultural differences (Gribich, 2013).

\section{Ethical Considerations}

Various ethical considerations were implemented throughout the research process. Prior to any data collection, an application was submitted to the Ryerson Ethics Board, outlining the various components of the proposed study including the research methodology and approach to be taken. All required and relevant documentation, such as recruitment letters, consent letters, 
research certification and interview guides were attached to the submitted request. I was granted approval from the Ryerson Ethics Board indicating that this study and research fulfilled all necessary requirements and followed the proper guidelines regarding methodology, recruitment, confidentiality, anonymity, potential risks, and potential benefits. The risks involved in this study were very low. However, a potential risk included feelings of emotional discomfort, which was alleviated by offering all participants the option to refrain from answering any question and withdraw from the study without any consequence.

Interested potential research participants were provided with a copy of the consent form to look over and sign if they decided to be involved in the study. Participants were not pressured into agreeing to participate and were encouraged to ask as many questions as they needed. Informed consent was acquired from participants as they were all provided with explicit information about the research project, confidentiality, anonymity, the dissemination of findings, as well as their right to skip over questions and withdraw from the study completely (Olson, 2011). In order to help cultivate a rapport with participants, and help them feel respected and autonomous, each participant was told that they would receive a copy of their transcribed interview which they could then edit to add or remove any information they chose. Additionally, each participant was told that they would receive a copy of the completed research paper.

\section{Recruitment}

Participants in this study were experienced educators in Ontario who were either drama or dance specialists or generalists using performance-based methods in their regular teaching practices. This included but was not limited to: dance, role drama, and play building (Fels \& Belliveau, 2008). In order to ensure that participants were suitable for the study, I consciously sampled teachers who were members of the Council of Ontario Drama and Dance Educators 
(CODE) list serve (Creswell, 2008). Fels and Belliveau (2008) suggested that performance-based pedagogical approaches are best suited for students in grades four through twelve, although they are adaptable to any age. Therefore, this study focused on educators working with students between the ages of eight to seventeen years old. The initial sample size was limited to four to six participants in order to devote sufficient attention to each individual and gain detailed, indepth information surrounding the topic (Olson, 2011).

My supervisor sent out a recruitment letter on my behalf to the gatekeeper of the CODE list serve (Appendix B) in order to respect the confidentiality of the names and emails of that network. All interested participants were instructed to contact me for more information regarding the study. In order to be considered for the study, participants had to be an experienced educator for at least five years in an Ontario school board, currently teaching, and who regularly, or who has regularly in the past, practiced performance-based methods with youth between the ages eight and eighteen in a classroom context. It was decided that the participants who responded to this recruitment letter would be selected based on a "first come, first serve" basis as long as they met the criteria for the study.

There were some minor challenges in the recruitment process. Based on the discussions with my interview participants, I gathered that all the teachers were extremely busy and I believe the general overload many teachers are feeling and facing, may have affected the response rate to the email. When five participants responded to the recruitment letter, one potential participant had just finished teacher's college and had very little experience using performance-based methods and I was therefore unable to include him/her in the study. 


\section{Participants}

Four teachers participated in my study. All participants were experienced teachers of over ten years, who were currently using performance-based methods with their students in grade four to grade twelve classrooms. In order to respect privacy and ensure anonymity, each participant was given a pseudonym.

Participant one: Greg* (pseudonym). Greg is a White male who is a certified English and drama teacher, and professional playwright. He has an undergraduate degree in English as well as a teaching degree. He has significant experience working in the professional theatre community for over twenty years and has been certified as a teacher for over fifteen years. He is currently employed as a high school drama and English teacher, located in a diverse urban city in southwestern Ontario, where he has taught for over a decade. Greg began working in professional theatre in 1989 as a playwright and has been practicing performance-based teaching methods for fourteen years. Through his work as an English and drama teacher he combines his passion for the performing arts with teaching.

Participant two: Sasha* (pseudonym). Sasha identified herself as a Black female from the African Diaspora. She is a certified teacher, professional dancer and dance teacher who has been teaching for over a decade. She began dance training as a child overseas, and later received a dance scholarship to university, where she underwent more extensive dance training and was competing on an international level. She came to Canada in the early 2000's where she continued to practice teaching and explore different areas of dance. She realized that she had a strong connection and passion for African dance and new communities that she learned about through dance. For the past five years she has been exploring various ways to share elements of her culture, empower students, and open discussion through the form of dance and performance. She 
also uses performance-based methods to open up discussions around other subjects in the curriculum such as history, geography and social studies. She is currently employed by an Ontario school board where she travels to various elementary, middle school and high schools on contract as their artist in residence. She was recently working at two different diverse schools in a southwestern Ontario city where she was able to create a dance-based unit based off the students she would be teaching and using the lens of immigration to explore what the idea of 'change' looks like.

Participant three: Nicole* (pseudonym). Nicole is a White female who is a certified drama and English teacher and has been teaching for over fifteen years. She has a degree in English and received her teaching degree in Ontario. Presently, she is employed at a diverse high school in an urban southwestern Ontario city where she teaches drama and English with grades nine through twelve. Nicole has been involved in professional theatre for over twenty years and has written, produced and performed in many theatrical pieces. She has extensive experience working with children with disabilities and has worked at many different schools in a diverse urban city in southwestern Ontario. Her use of performance-based methods has been central to her teaching for the past twenty years although theatre and working with youth has always been a large part of her life.

Participant four: Kaitlin* (pseudonym). Kaitlin is a White female who is a certified English and drama teacher at an arts-based high school located in southwestern Ontario. She received her Honours Bachelor of Arts from a Canadian university where she minored in drama and majored in English. After graduating from a faculty of education, she went on to complete her Master of Education degree at a university in the United Kingdom. She has been teaching for over fifteen years and currently teaches English, drama, and gender studies to high school 
students in grades nine through twelve. She was initially drawn to drama when she was growing up because it allowed a lot of flexibility in the subject matter and encouraged open conversation. She has used drama and performance-based methods in her teaching for over fifteen years.

\section{Data Collection}

Data collection was achieved through the use of semi-structured, one-on-one interviews and field notes. This process of data collection was chosen because it allowed participants to address specific dimensions of the research questions and express their experiences, while also maintaining the relaxed and flexible qualities of unstructured interviewing (Galletta, 2013). A semi-structured interview guide (Appendix F) was created to provide some guidance to the participants and offer some initial entry points for discussion (Creswell, 2008). Additionally, semi-structured interview questions ensured that participants did not venture too far off topic. In order to ensure participants did not feel too guided by the interview questions, they were told they could express themselves however they wanted and were encouraged to speak freely, even if it moved away from the posed interview question. The interview guide included many openended questions in order to create an opportunity for participants to speak their truth without being constrained (Creswell, 2008).

Due to response time for participants, the interviews were conducted over an eight-week period in a location of the participants' choice of convenience. If the participant did not suggest a preferred location, a meeting room at Ryerson University was used to hold the interview. There was one interview session per each participant, each interview ranging from approximately fortyfive minutes to one hour in length. Prior to beginning the interview, I established a comfortable, relaxed environment through general, pleasant conversation with the participant. The interview questions I used included background, experiences inside and outside the school context, opinion 
and emotive questions (King \& Horrocks, 2010). Samples of the types of questions I would ask were given to all participants prior to their interview. In order to address the participants' background, I asked them how long they had been teaching and using performance-based methods with youth. Participants were asked to describe what aspects of performance resonated with them and talk about their own experiences using these methods, as well as how they believed these methods were valuable in the teaching of youth. Additionally, questions around what specific kinds of performative practices were used, and what topics were addressed through these methods, were asked. In order to elicit more information from participants, probes were used, although very sparingly, as many participants had a lot to say and needed little encouragement sharing (Creswell, 2014).

\section{Confidentiality and Anonymity}

As a researcher, it is crucial that I ensure the protection of my participants, build trust, and ensure that their personal information is safely contained with no possibility of misconduct (Creswell, 2014). In order to meet these crucial requirements, I ensured that confidentiality and anonymity were maintained throughout the entire research and writing process. All consent letters, field notes, audio files and interview transcriptions were downloaded on to a password protected USB drive and kept in a secured cabinet in my supervisor's office at Ryerson University.

\section{Authenticity and Rigour}

As Gribich (2013) explained, the underpinning ideology of qualitative research emphasizes the importance of maintaining validity and authenticity through the accurate representation of the perspectives of participants with lived experience. Peer debriefing and participant checks were also used following the preliminary data analysis in order to further 
ensure validity (Gribich, 2013). All interviews were audio-recorded in order to obtain as much detail as possible from the participants and to ensure a transcript could be prepared, which was then used for analysis (Olson, 2011). Notes were taken in a research journal during the interview in order to ensure no information would be lost in the case of any sort of technical failure with the audio-recording. Each participant was emailed a copy of their interview transcript to read and edit at their own accord. All participants were given two weeks to include or remove any information from their interview. All findings were written in a detailed manner in order to accurately and truthfully represent the voice of the research participants (Creswell, 2014).

\section{Data Analysis}

The data collected in this research was analyzed through a qualitative thematic analysis. The data set included four interviews and their corresponding transcripts as well as field notes made during the interview. Each participant's perspectives and experiences were carefully examined and organized into themes through a block and file approach. As outlined by Gribich (2013) a block and file approach best suits instances where the researcher wishes to keep the data largely intact. In a block and file approach, relevant themes are first established and then responses are categorized under these labels (Gribich, 2013). Through the block and file approach, I was able to include enough detail to ensure the data remained valid and representative of the participants' perspective.

A thematic analysis was chosen as its flexibility allows the researcher to notice hidden concepts and key ideas that they may not have considered during their initial data collection (Gribich, 2013). The first step to the block and file approach is identifying the relevant data and developing a list of participant responses (Gribich, 2013). As Gribich (2013) stressed, the descriptions of participants' responses must be reflective of the data collected. The second step 
of the block and file approach includes the grouping of participants' responses under broad headings, which will eventually become the central themes, to help organize the data (Gribich, 2013). Thematic analysis recognizes that certain themes may need to be broken down or changed as more data is added, and allows for this to easily occur (Gribich, 2013). As Gribich (2013) suggests, once this process is finalized it, the data is displayed through themes, with easily accessible quotes and case studies readily available to the researcher.

I began the thematic analysis process by first transcribing each audio-recording file verbatim using a consistent style for each participant (Olson, 2011). Throughout the transcription process, I was able to familiarize myself with the data and initiate data analysis procedures. After reading each transcript and developing a sense of understanding around the data, I created initial themes for each question and organized participants' responses under the corresponding theme (Gribich, 2013). The block and file approach was used for each research question, until all responses had been blocked and filed under various general themes (Gribich, 2013). Themes that were similar amongst different research questions were combined to create overarching themes (Gribich, 2013). As King and Horrocks (2010) noted, a theme can be understood as a "recurrent and distinctive feature(s) of participants' accounts, characterizing particular perceptions and/or experiences, which the researcher sees as relevant to the research question" (p.150). As a result, there were four themes that emerged from the data, all of which were directly related to the research questions surrounding teachers' experiences with integrating performance-based teaching practices in their classrooms and were supported by direct quotes from each participant.

\section{Summary}

The aim of this qualitative critical ethnographic research design is to address the research questions I created surrounding the ways in which racial, cultural and social difference is 
predominantly conceptualized within the education system. Of significance are the potential implications of this research for both teachers and adolescent students alike, and how performance can be utilized as a critical pedagogical method in the teaching of difference. The use of one-on-one interviews allowed me to engage with participants about their personal experiences with performance in their own lives as well as how they have incorporated performance into their teaching approaches and the impact this has had on students. Each participant had informed consent and was made aware of how the data would be collected and disseminated. All precautions pertaining to the confidentiality and anonymity were discussed with the participants and maintained throughout the research process. The use of a thematic analysis approach to analyze the data allowed for an accurate representation of the data that was collected through the use of relevant themes. The following chapter will provide the findings that emerged from the interviews. 


\section{CHAPTER 4}

\section{Findings}

This research study examined elementary and high school teachers' perceptions of the integration of performance-based practices with youth in educational settings. Specifically, this inquiry investigated how teachers can utilize performance as a critical pedagogical tool in the teaching of social, cultural and racial difference and what the implications of this are for their students as well as themselves. Four semi-structured interviews were conducted with elementary and high school teachers in Southern Ontario. Conducting private, one-on-one interviews allowed teachers to speak freely about their experiences with performance-based art in their own lives and how they have implemented these practices in their teaching of youth particularly involving subjects of difference, oppression and power relations. Through the use of a thematic analytic approach, four central themes emerged that were reflective of the data collected from the interviews.

The first theme explored the various motivating influences for the incorporation of performance-based practices within the learning environment. The second theme addressed the specific practices that were used within the classroom, as well as the characteristics of the school environment and student body. The third theme discussed teachers' observations of their students and the perceived benefits of implementing various performance-based practices within the classroom. Specifically, this theme described how performance can be a useful tool in addressing power relations, racial, cultural and social difference, and oppression. The fourth theme discussed the challenges participants faced initiating conversation around these topics with students and the difficulties involved in integrating performance-based teaching practices within the classroom. 


\section{Motivating Factors for the Inclusion of Performance-Based Teaching Practices}

Greg began learning about and practicing drama early in his life through his career as a professional playwright. It was not until after he became a full-time high school teacher that he began incorporating performance-based practices into his daily teachings. Teaching grades 9-12 in a highly diverse, inner city school, he noticed increasing levels of anxiety that he felt needed to be addressed.

Greg: Not only do we have high levels of racial, cultural and social diversity but we also have 'neuro-diversity' which is a pervasive factor in classrooms right now. I use the term 'neuro-diverse' to describe the diversity amongst students in terms of their mental health and well-being. Some students have anxiety, while some have bi-polar disorder, and others, who go through different issues in relation to sexuality or other aspects of their identity.

Greg's experiences within the professional theatre community helped develop his understanding of performance and performance-based learning, making it an integral part of his everyday teaching practices with students. His approach to teaching focuses on implementing a sense of structure and collectivity in the classroom. Greg described the inclusion of performancebased learning as:

Adding a repetitive structure to the learning environment where students can perform sequentially on different levels based on what type of activity they're doing...this can be applied to many different subjects as it focuses on skill development through repetition, practice and collaboration.

This framework of performance-based learning provided students with a model that allowed them to continuously practice and work towards academic and personal achievements. 
Sasha was motivated to integrate performance-based practices into her teaching with youth as a result of her own experiences growing up in an education system that lacked Black teachers and cultural representation that reflected her identity. This fueled her desire to empower marginalized students to explore the nuances of their own identities and express their culture. Having been a professional dancer and dance teacher for many years, Sasha has always had a passion for the art of dance and performance. However, it was not until she moved to Canada and began practicing forms of African dance, that she realized the power of dance and performance in terms of its capacity to tell stories, explore identity and build communities. This realization inspired Sasha to share this practice with young students who were in the midst of learning about their own identities, as well as the cultures of others.

As an artist emerging from the African diaspora, her use of performance seeks to provide students with the ability to challenge traditional processes of learning and knowledge.

Sasha: This kind of learning is about the entire process and students showing and reflecting on what they have gathered through this process. This idea of "this is what we know and that is it," does not work for me and I would hope these tools can be used by my students in their daily lives, like unpacking a particular topic or discussing the process of how knowledge is formulated.

Sasha also discussed the importance of the inclusion of performance-based practice and open conversations about power, difference and identity in the classroom. Specifically, she noted that performative practices that encourage self-exploration and expression is particularly valuable for Black girls and young women. 
Sasha: Imagine the young Black children who have never been taught about their roots or culture in the curriculum. They do not see themselves. I have a daughter coming up and I am trying to do this for her. We have to have these conversations now.

Nicole further described the significance of including performance-based practices into her classroom as a way for students to build confidence, develop critical thinking skills, and overcome personal struggles. Nicole has always worked with students varying in levels of ability and mental health, as well as diverse socioeconomic statuses, and cultures and is passionate about helping students who are constantly dealing with a variety of complex issues, thoughts and emotions.

Nicole: I was one of those students myself, I have gone through my own challenges and those experiences are what has pushed me to help kids that are going through their own issues. I have always been committed to working with youth. The difference that I make with these students is the reason why I am still here and why I am still teaching.

Due to the prevalence of anxiety and varying needs of her students, she felt that incorporating drama and performance-based practices in the classroom were conducive to creating a safe and engaging learning environment. She noted that her classroom was a place where students were encouraged to pose questions and explore subject matter that interested or concerned them.

Kaitlin further discussed the importance of including performance-based practices within her daily teaching routine as a way for young people to express their identity and address struggles, or topics that they felt strongly about. Her inclination to incorporate these methods also stemmed from her own personal experience with drama in the education system and the desire to express herself freely in ways that were not typically encouraged in other classes. After 
practicing and studying drama for years, Kaitlin became a full time high-school drama, English and gender studies teacher.

Kaitlin: The reason why I was drawn to drama when I was in high school was because it was a subject where I felt like we could talk about anything. I felt like nothing was off limits and that any topic or issue could be explored and it was really exciting to me because, as I always say, you have to make art about something, so to me, it is a very malleable art form because so many topics can be explored.

Important were the various motivating factors that led the participants to begin practicing drama and dance, as well as reasons for integrating personal practice and passion for performance into their daily teaching routines in their classrooms. They were passionate about providing students with an open forum to begin inquiry on topics that resonated with them. Additionally, all were interested in students strengthening their sense of self-confidence and analytical skills through various applications of drama, dance and performativity.

Greg, Sasha and Nicole all came from backgrounds as professional artists whereas Kaitlin developed an interest in performance early on in school and continued her work through graduate courses. While each participant had their own situated experiences and distinct connections to performance which undoubtedly influenced their teaching approach, the motivating factors of all educators shared some commonalities. These stemmed from an interest to ensure students' well-being and address their concerns. As well, the acknowledgement of the growing levels of diversity amongst classrooms prompted the implementation of various performance-based practices into the classroom setting. This supports the central research questions through the collective acknowledgment that it is imperative for educators to address the increasing diversity in Ontario classrooms. Additionally, they unanimously agreed that 
performance-based practices are highly valuable in the teaching of racial, social and cultural difference, thus confirming that alternative pedagogical approaches are necessary to adopt in the modern Canadian educational landscape.

\section{Practices Used in the Classroom}

Each participant discussed the various ways in which they incorporated performance into their classroom. Their particular approaches were conceptualized and structured to best suit their respective learning environment and address their students' needs. The characteristics of their classrooms and school were also described.

Greg integrated performance into all of his teachable subjects which included: Drama, English, Gender Studies and Media Literacy, in various ways. Given the high levels of anxiety in his classroom, he heavily structures his drama classes. His grade 12 class is taught early in the morning which is challenging for many students. Several of them have jobs that require them to work long hours into the night, as well as disrupted home environments. In order to focus students and collectivize the class, he begins the day with a physical warm-up.

Greg: I start with a physical warm-up which is just a variation on sun salutation ...this is where we begin to try and create a mutual sense of purpose. Then, we will immediately go into an improv warm up where they go into improvisation techniques.

In his drama class, there are a variety of talents and ability levels which makes it difficult to create a community in the classroom, as everyone is a bit wary of one another. For this reason, Greg tries to engage all the students in his class by having them constantly perform with and for each other. 
As Greg stated:

I'm mostly script-based in my drama teaching from a performance aspect. I've moved into the idea that there's constant structure in what everybody's doing so we work with different kinds of scene forms in which everybody is equally pursuing sort of the same kind of performance goals. Everyone is performing every day, at least twice, and basically in this performative structure students learn to appreciate what other people are doing and learn from what other people are doing.

In addition to incorporating performance-based practices within his drama class, he also emphasized the value in adopting a performance-based approach to the other subjects he teaches, specifically through the process of repetition. In his media studies class, for instance, Greg will present his students with various media images. Collectively, he and his class will continuously discuss and critically examine the different images which has led to the development of strong analytical thinking skills amongst his students.

Greg: We discuss the nature of different pictures and we go through image after image, so there is repetition, which is to a certain extent performative in terms of how they relate to the images. And in doing so you start to strengthen their ideas of how narratives are constructed consistently so they can see patterns in the subject matter and in the culture itself.

This strongly connects with Duffy's (2010) work, which emphasized the importance of imagery and non-verbal performance. Duffy (2010) noted that images tend to resonate with young people in particular. Therefore, visually teaching students to identify instances of oppression through media imagery would be considered a critical, performative practice. 
When implementing performance-based practices into her classroom, Sasha would often adapt her subject matter to reflect the group of students she would be teaching. This was a crucial aspect of her work, as she moved around to many different learning environments either showcasing her travelling exhibit or teaching a performance unit as an artist in residence and has therefore worked with a wide range of students. Similar to Greg, Sasha's inclusion of dance in the classroom is largely focused on integrating the process of performance into her daily teaching, where discussion and reflection are valued just as much as the movement aspect of a performative piece.

Sasha: Performance-based learning for me would be where the goal is to deconstruct a performance piece and this deconstruction leads into lessons that talk about what it could be or how it was perceived. It could be from the perspective of the person that created it, it could be just feelings in the room about what people felt when they saw it. Sometimes in dance programs or dance workshops that I'm asked to do people really emphasize the last performance at the end. But for me it's more about the process as opposed to the performance. I leave it up to the young people, I ask them who they want to perform with and why they want to perform.

Sasha's performance-based teaching approach is heavily focused on the connection between movement, spirituality and culture. As an artist whose identity is central to her work and sense of being, she is not simply interested in teaching the technical aspects of dance, as she had learned growing up, but rather fostering a space where young people, especially marginalized students, can begin to strengthen their relationship with their mind, body and spirit through movement and self-reflection. 
She offered the following example:

So, just an experience I had a couple of weeks ago. I went up North and did a retreat with a bunch of young women, and we were doing a beading exercise and just talking and a lot and I told them about how one day I was introduced to African dance and just hearing the drums and how it made my body feel, this connection that I never even knew ran through my blood or my muscle memory. And the room went quiet and I told them that we were all going to try it and that it wasn't so much about the steps, it is more so the connection in the steps and why they're doing the steps and it's more so just a right of passage in the community where dance was just as much a part of their lives like going to the doctor, or graduating, or giving birth.

Sasha discussed how her classical training restricted her from freely expressing her individuality. She further noted how dance enabled her students to connect with their identities in a new, liberating way. She offered:

I feel like my classical tools have helped me, but it also restricts my spirit and who I am as a person. That's why I choose to go around to different spaces and put different ideas on the table... Watching girls take in the music and move in ways they've never moved before - being open to that experience and really connecting with themselves is what dance is all about, it's the freedom of it.

Since Sasha works with many different schools, she often adapts her subject matter to reflect the specific needs of her students, many of whom are new immigrants and first-generation Canadians and are adapting to many cultural changes and challenges. She believes that dance is a malleable art form that can be used to explore a wide variety of topics and she is committed to ensuring that students see themselves represented in the subject matter. 
Sasha: We'll have a theme that we're talking about and then the activity will go with the theme and then we'll stop and we'll talk. There's a lot of stopping and talking throughout the creative process, while the students are working on their pieces where I'll say, "why did you choose to do this?” And then it sparks a conversation. It isn't always moving and dancing because we need to decompress and talk about it. I try to link my activities to what it means to them and what comes up for them and then have them talk to each other about it and be okay afterwards.

Sasha offered an example of when she was working in a school with new immigrants to Canada. She decided to use immigration as a lens to discuss the theme of change. Specifically, she was interested in exploring what change looked like through movement and the feelings this evoked for her students. She said:

Collaborating with a photographer, we set up photos around the class of children in various refugee camps around the world...Collectively, we as a class discussed how these images made us feel and what emotions we thought the children in the photos were feeling.

After providing visual imagery and context, Sasha introduced a set of movements to her class. The idea of being expressive through movement can be challenging for students who are not used to being taught through performance-based practices. For this reason, she teaches her students a few dance steps that they can then apply anyway they feel comfortable with. As offered by Sasha:

These movements are not set in stone. We're all moving beings and I encourage my students to create their own narrative around the photographs or whatever they happen to 
be feeling in that moment. Then we'll incorporate some music and how they're feeling and their movements might change with that, it's about what works for them.

Like Sasha and Greg, the third participant, Nicole described the significance of the process of performance. Central to her teaching approach is the idea that critical discussion and performative exercises are not mutually exclusive, but rather, both highly valuable and necessary in the process of learning through these active practices. Nicole also emphasized the importance of adapting her teaching approach to reflect the particular group of students that are being taught.

Nicole: I think of it as process versus performance. I am a performance-based teacher and I use a professional theater process drama approach. I believe that kids should be able to explore subject matter, and acting, performing, using their voice allows them to do so. I incorporate a lot of performance-based exercises in my teaching, whether it's improv games, tableaux, or more scripted performance pieces.

Similar to the other participants, Kaitlin used various performance-based practices in her classroom that focused on the process of performance, such as the discussion surrounding a particular topic that is then explored through a performative approach. Concrete drama techniques were also incorporated into her daily teaching practices in all of her teachable subjects.

Kaitlin: Many of the students here learn best through the arts and they typically take a lot of arts courses, so I would say performance-based practices do play a big role in all of my courses. It's pretty common that I would incorporate scripts, both reading and writing, into my English class. In Gender Studies, we'll do some role stuff where we get up on our feet and do some role-playing activities. 
Kaitlin was the only participant to directly address Augusto Boal's, Theatre of the Oppressed (1979) and had incorporated his work into her class curriculum.

Kaitlin: In my grade 10 drama class, we are doing a unit on Theatre of the Oppressed, which was originated by Augusto Boal, and we are exploring how theatre can be to entertain but theatre can also be a social and political tool for changing the world and allowing people to address injustice and power dynamics, and such. So, in this unit we do a lot of Boal's games, and we do some Forum Theater and Image Theatre to look at issues of oppression. For Forum Theatre we would stage a situation where someone is being oppressed. I'll make up scenarios like, you missed your curfew and your parents grounded you and then someone could go up and then tap them out and take on their role and then try a different way to solve the situation.

Kaitlin works with her students using drama as a problem-solving tool to explore power relations through theatrical forms. She explained how she used multimedia as a point of inquiry to discuss power, identity and oppression with her class. As Kaitlin described:

This year, each group of students got a different source to work from. So, one group had a photograph from a Black Lives Matter protest, then another group had a piece of text, like a poem from Audrey Lorde, and then another group had a song, and they had to use some of the different techniques that we explored in class to critically engage with them. Each group then had to write a performance piece and present their work to the class. Afterwards, we debriefed and discussed the pieces.

She talked about the importance of understanding and representing ideas in more abstract ways. Further, Kaitlin noticed her students expanding their range of performance and opening their minds to new modes of expression, such as dance, through these practices. 
Using performance-based teaching approaches, such as improvisation, role playing, script-writing and Boal's (1979) TO techniques, provides students a space to freely express their thoughts, feelings and concerns. Additionally, placing a focus on the process of performance through the implementation of specific components such as repetition, and visual learning through multimedia, within the classroom, allows students to thoroughly explore subject matter that resonates with them, engage with ideas at their own pace and strengthen their analytical skills. By integrating these different strategies into an educational setting, teachers were able to observe and identify several perceived benefits that resulted from these practices.

\section{Benefits of Performance-Based Practices with Youth}

All participants discussed the perceived benefits that they observed through implementing performance-based practices into the classroom environment. Each one described how these methods were useful in addressing topics of power, difference, identity, and oppression, which strongly connects to Boal's (1979) Theatre of the Oppressed. Greg described one of the main benefits of including performance-based practices into his daily teaching with his high school students is that it challenges predominant standardized models of education and, instead, promotes critical thinking and allows students to freely explore subject matter.

Greg: Performance-based strategies encourage and allow students to think outside this idea of 'what is the right answer?' which is definitely important. It allows them to take control of the subject themselves. This is where we have to get to as we prepare kids for university now. How to take control of your subject matter, your learning and your understanding of it and not feeling like the answer lies outside of what you're doing. In his classroom, Greg noticed that students responded well to performance-based methods which included both obvious forms of performance, such as script-based drama, as well 
as more subtle components of the process of performance such as repetition, and open dialogue, which he incorporated into all of his classes. He found that these factors were particularly useful amongst his highly diverse class, as it offered students the tools to understand and articulate their lived experiences, which in turn helped to address symptoms of depression and anxiety that many of them face due to a wide variety of factors.

Greg: My classrooms are predominantly Black, and male. What we're doing now is dealing with issues of White supremacy and issues of phallocentrism. I'm using media imagery right now with my grade 12 class so I'll go through different media imagery and we'll discuss why certain images mean what they mean in relation to narratives, in relation to masculinity, femininity, race, and mythically normative identities.

In Greg's drama class, he noticed that students were able to express themselves through performance, which worked to normalize different forms of cultural expression and strengthen understandings of difference amongst the class. He discussed the various ways in which his class explores their own identities as well as those of their classmates through performance. Specifically, he described how his students will often perform scenes that focus heavily on relationships, which raise different conversations surrounding sexuality and race in the class.

Like Sasha, Greg primarily teaches racially diverse students. He discussed how the lived experiences and identities of his students strongly influence the subject matter and dialogue that is explored in his class. He emphasized that his classroom is a safe space where students are able to experiment and freely express their authentic selves. He noted that many of his students use performance to take ownership of 'street' language and explore other dimensions of their identity. Despite many of his students feeling comfortable enough amongst each other to share jokes, Greg discussed the limitations of these cultural exchanges. He noted that the few non- 
Black students in his class are well aware that they are not to use certain terms or make the same jokes as their Black classmates. Specifically, he discussed how his non-Black students understand that these narratives of identity are to only be told by those whom have lived experience, for example when two Black students use the 'N' word.

Sasha also perceived there to be several benefits from practicing performance-based methods with her students. She noticed that using performance was highly valuable in expressing aspects of identity and addressing social and cultural differences amongst students. While many of the White students that Sasha has worked with enjoyed aspects of African American culture, especially dance, they lacked the contextual knowledge of that artform and this can come across as disrespectful. Sasha attempts to address this void of cultural awareness amongst some of her students by combining dance with a dialogue about African American culture and history. She offered the following example:

I say to them, "hey, those dances are great, but do you know where those dances are from?" And I say, "they're rooted in..." And then I'll go off into my thing and say, “they're rooted from people of the African Diaspora and they're social dances. They're to have conversations or to get people to move and they have evolved over time but this is the root. And these inventors that you're seeing are, too, from the same place, dancing is just a small part of the culture, don't be fearful of being able to reach out and acknowledge that things like light boxes and mailboxes were invented by people from the African diaspora." A lot of the time in schools it's this regurgitation of stuff that they've seen on YouTube these dances - which is great, I love it, but I challenge them. 
Sasha noticed that not only can performance open up meaningful discussion on cultural difference it can also work to bring different communities together and explore identity in an honest and authentic manner.

Sasha: Dance can tell people's stories, their families stories, their ancestors stories, in a way that goes beyond reading it in a book or showing it in a video, they can even mix it in a video, it hits you differently, it's personal, it's honest, it's authentic, you're seeing other people do it. You can find bits that you connect to, that speak to your story. And not everyone can read a book and get the gist of it.

Through the integration of performance-based methods, Sasha observed a significant increase in self-confidence amongst her students, particularly amongst young, Black female students, as well as an overall improvement in class dynamics and students' personal habits. Sasha: Through performance students can lose and find themselves at the same time, they build confidence. I do what I do because of those moments when I see kids breathe and change and apply themselves and it's not even about the steps. It's when I can see the impact that dance has on these kids, this is what made me want to go to teacher's college. Seeing what it does to the heavy girl who you bring to the front of a class and you say, "do it again, you did that great!" Or asking the kids to lead the class and for them to be acknowledged and tell them, “good job!" It's really basic stuff but it doesn't happen all the time. And seeing girls have confidence and seeing how they walk into a room. It's very powerful.

Nicole also discussed her perceptions of the benefits of the performance-based practices she had incorporated in her high school classroom. She noticed that students build selfconfidence and learn to express themselves through experimenting with different roles and 
hypothetical situations in various drama scenes in ways that they otherwise would not get to experience in other classes that do not use performance-based methods.

Nicole: Performance, being present, public speaking, it is all a part of building confidence and self-esteem. It allows students to have a voice and be heard. Drama actually allows students to be in different positions, which you don't really get anywhere else. Our vocal unit in particular, is really useful in helping students build that strength and confidence. She noticed that performance-based practices were highly beneficial to students whose first language was not English, as it allowed them to practice their verbal and non-verbal communication skills and prepare for different situations they may come across in their daily lives.

Nicole: Performance-based learning can be particularly useful to ESL students and can help them learn the language and put them in actual situations that they might experience in their day to day lives and it builds confidence in that sense.

Lastly, Kaitlin observed many perceived benefits of implementing performance-based practices with her high school students. She emphasized how the implementation of drama and performance in the classroom was useful in exploring topics of power and oppression with her students.

Kaitlin: We try and talk about theatre almost as a problem-solving tool and then usually we explore the concept of power or oppression through theatrical forms.

She noted that performance-based methods are particularly useful when discussing power imbalances because it provides a visual example that resonates with young people.

Kaitlin: Part of it is being able to see it, I think sometimes when you can see things, you are able to better understand them. Boal has the 'Great Game of Power,' where you put 8 
or 9 chairs on stage, and you tell students that they can go up on stage and rearrange the chairs in such a way to suggest power. The whole game is done in silence where just one student, after another, will go on stage and rearrange the chairs. I find this very powerful and my students do too. They are able to actually see what's powerful and what's not powerful. When the game is over we'll talk about it.

She noticed that her students developed a stronger sense of empathy, become more aware of their behaviour and felt able to freely express their feelings and thoughts.

Kaitlin: Another powerful part of drama is the feeling aspect of it, you don't just understand something intellectually - you feel it. You might feel how that other person feels and have empathy and that's what makes drama a good tool. It's not just intellectual learning, it's emotional. Performance-based practices often evoke emotional responses from students in my classrooms. Anytime you're talking about social issues things will come up and students will talk about their experiences.

Through engaging in performance-based activities, Kaitlin observed her students becoming increasingly self-reflective and more critical of the world around them, specifically surrounding issues of power relations, oppression and identity. Kaitlin offered an example of this:

At the end of the year my grade 10 class does docu- dramas where they might take a specific event in history and research it and then create a performance piece around it. The assignment required each group to create a performance piece based on the particular historical event they researched. Since many of these events took place in various countries throughout the world, students portrayed different cultural identities. She noted that this activity led to a collective class discussion surrounding cultural appropriation and representation. 
As Kaitlin described:

Last year some of the events my students explored were Japanese internment camps, the Khmer Rouge in Cambodia, and residential schools. The prevailing thought right now is that you shouldn't have White kids playing Indigenous roles on stage. Last year, when we were doing the docu-dramas, I was beginning to feel very uncomfortable with it all and I actually asked the kids at the end, I said, "there are these issues around role and whether it's appropriate." And they said that they thought they should be able to take on these roles and tell these stories because it's important to learn but we have to be responsible and sensitive. And I remember there was one group, the group that did Japanese internment camps and they said, "I don't think we were responsible, I don't think we did enough research and we made stuff up and I don't think that was appropriate," which I thought was great. It was a really good learning experience.

Although many of her students initially felt like they should be able to take on roles of characters of other races, and cultural backgrounds, they later came to the realization that this can often be inappropriate. Further this activity spoke to the power of performance as being a deeply self-reflexive practice and valuable tool in developing one's understanding of identity, difference and power and communicating through conflict.

\section{Challenges Participants Faced}

Arising from his motivation for practicing performance-based methods with his students, Greg described some of the challenges he experienced with implementing these strategies with his class. He felt that some of the issues commonly experienced by his students, such as high levels of anxiety and disrupted home situations, contributed to the behaviour of his class. He noted that many of them act out and are disruptive in the classroom as a way to make themselves 
feel more secure in their educational environment. Greg was hesitant to problematize his students' behaviour, as it was apparent he had a high level of respect for his students and a deep understanding of their lived realities. However, he did note that, at times, his students' tendency to act out impeded his ability to effectively engage the rest of the students in a particular activity. Greg: There is a lot of acting out in class rooms right now because it makes students feel secure. Because everyone is reacting to the students' actions, in a sense, they are controlling everyone else. When everyone is looking at you and seeing what you're doing, then the student feels secure in knowing that no one's not doing anything that they don't know about. So, we see a lot of that going on in a lot of different classrooms.

He also felt as though there was never enough time to complete every activity which led to a bit of a tension amongst students who felt like they needed more time to complete a particular exercise.

Sasha expressed that one of the issues she faces with implementing dance and other new practices in the classroom is that the school board is not constructed in such a way that prioritizes this kind of learning. As a result, she has had to negotiate with administrators and other teachers who challenge her methods and attempt to control her work with her students.

Sasha: I've had some backlash, people will come in and feel like they need to interject or control the space. Some administrators and teachers get worried they want to contain things and I just say these kids need to be free! I've been in situations where the kids are getting yelled at by teachers and the kids are getting stressed and that's not a positive learning environment or safe space for these students.

Sasha did not note any challenges trying to implement performance-based practices with her students. However, she expressed some anxiety about the future of the education landscape, 
emphasizing her hopes for the further inclusion of these practices and open discussions of culture and difference in more classrooms.

Sasha: So many of these schools refrain from having these discussions about cultural differences and identity out of fear. Teachers often do not know what to say or how to approach a particular topic. So how do we navigate this and make kids feel safe? And the answer to this is that there are people who do this work, bring them in the school! Get the support! Prioritize it and believe in it!

Like Sasha, Nicole felt the pressure and stress of negotiating with administrators and the school board system when trying to implement alternative teaching practices within her classroom.

Nicole: The school board can really hamper progress. Policy is a big issue. The board level is more disassociated from what is actually going on within the school and these classrooms. They are not particularly supportive of my teaching methods or any form of alternative teaching in general.

She also described some of the challenges she faced as a teacher using these methods with her students. Specifically, she felt that it was difficult at times to use performance-based methods with her students, while still maintaining a level of control and structure within her classroom. Additionally, she noted that some students are hesitant to engage in performancebased methods out of anxiety and fear. However, she suggested that these challenges often open up space for discussion, which led to important learning experiences for her class and herself. Nicole: As a teacher, I am constantly negotiating how I can be a leader and not be too politically correct without being offensive to anyone, which is increasingly become a difficult task. We have had scenes where the language has been offensive, either to me or 
other students, and we've had to shut those performances down but open it up to the class to discuss what specifically about that scene was problematic. There is lots of room for discussion always. There are also issues around some students not wanting to engage in the performance aspect, either they do not want their voice to be heard, or they're afraid. Kaitlin did not notice any issues trying to incorporate performance-based practices into her classroom, but described the challenges surrounding discussions of power, difference and oppression with her students.

Kaitlin: I think it's easy to be a teacher and avoid issues of race and diversity. You can also just pay lip service to it. If you look at the Ontario curriculum, it's very broad and it's really just a bunch of suggestions. We really have a lot of freedom to design our own content and choose materials that we want to teach and even more so at this school because we have a principal who really trusts us. Students genuinely want to talk and learn about these topics, it's on their minds. But for teachers, it's a scary prospect because a lot of these teachers don't know enough about these issues because they weren't taught about them and I tell my students that I didn't learn about this stuff. So, there's a pressure that teachers feel, whether it's right or wrong, to be experts. And so, if you're a teacher that feels a lot of pressure to be an expert then you're not going to teach things that you don't know a lot about.

Educators identified several perceived benefits of incorporating performance-based practices with students ages 8-17 such as an increase in self-confidence, strengthened sense of self and a general sense of empowerment. They also expressed some of the various challenges they experienced implementing performative methods in their classroom, such as push-back from administrators, disruptive students and a lack of preparation to effectively address issues 
surrounding racial, social and cultural differences. A common theme in the successful implementation of performance-based practices surrounded addressing students' anxieties and specific needs. With students being more racially, socially and culturally diverse than ever before, and with mental health becoming an increasingly pervasive factor in Canadian classrooms, the educators found that it was difficult to successfully execute performance-based activities at times when students felt particularly vulnerable in the classroom. The following chapter will draw connections between the literature and participant responses by examining the findings involving the practices used, perceived benefits of integrating performance and the feasibility of including these methods into an educational setting. 


\section{CHAPTER 5}

\section{Discussion}

\section{Overview}

The purpose of this study was to explore the ways in which youth are taught within the Canadian education system, Ontario specifically, about topics surrounding difference and power and how this influences students' understandings of the systemic oppression of marginalized groups and the construction of identity. Through examining how performance-based practices could be utilized as a critical pedagogical tool in addressing issues surrounding these challenging topics, this inquiry aimed to offer insight into elementary (grades K-8) and high school (grades 9-12) educators' experiences using these methods in their classroom. The findings discussed the participants' motivating factors for incorporating performative methods into their classrooms. Details of the specific practices used were also discussed. Other themes that emerged included perceived benefits of these approaches, as well as the challenges associated with implementing performative methods within the educational setting and using these practices to address topics of difference, power relations and oppression.

The participants described some of the common performative practices they used in their classrooms which included dance, drama, docu-drama, script-writing, role-playing, improvisation and Boal's (1979) Theatre of the Oppressed (TO) techniques such as Forum Theatre. Additionally, they all placed a focus on the process of performance, which emphasized critical discussion, media literacy, repetition and problem-posing. Educators noticed that by implementing performance-based practices in the classroom, students became more selfreflexive, empathetic, and self-confident. Through educators initiating open dialogue around topics surrounding power, oppression, and difference, students were able to share their thoughts 
and feelings concerning aspects of their lived experiences and particular identities. This is significant as several studies (Boler \& Zembylas, 2003; Solomon \& Singer, 2011; James, 2012; Ghosh \& Galczynski, 2014) have suggested that existing power imbalances within the educational setting contribute to the ways in which students of different social, racial and cultural backgrounds come to understand their own identities as well as the identities of others. By addressing difference instead of minimalizing it, students and educators are able to move towards a more equitable pedagogical framework (Dei, 2007; 2014a).

Educators expressed their motivation for incorporating performance-based practices in the classroom as a result of their own passion for performance art and desire for their students to freely express themselves and strengthen their analytical thinking skills. Many educators also felt that performative teaching methods were useful in addressing many of the issues young people currently face such as high levels of anxiety, low self-esteem, and confused sense of self. However, due to rigid school administrations and education policies, lack of time, and disruptive classroom environments, participants found it difficult at times to implement critical performative practices with their students. Additionally, some participants experienced challenges addressing topics surrounding power, identity, difference, and oppression due to a lack of confidence to speak on a topic that they were not properly trained to teach. As various studies (Dei, 2007, 2014a; Solomon \& Singer, 2011; Daniel, 2016) indicated, one of the prevalent issues facing the Canadian educational landscape is the unwillingness of educators to address pressing issues of inequity in the classroom. This is largely due to the fact that the preparation of educators consistently disregards the value of social justice, inclusive discourse and equitable educational practices despite Canada's increasingly diverse population (Solomon \& Singer, 2011 \& Daniel, 2016). 


\section{Practices Used in the Classroom}

As prior studies have noted, Canada has long participated and continues to engage in many forms of systemic racism, such as the oppression and marginalization of many groups of people (Solomon \& Singer, 2011, Daniel, 2016). Although there have been attempts to implement multicultural education programs in schools, many marginalized students continue to express concerns about racism and discrimination (Dei, 2007; 2014a; Ghosh \& Galczynski, 2014; Daniel, 2016). Considering the disparities between a predominantly White teaching force and a rapidly growing diverse student population there is a dramatic divide between non-White students and White educators who have not been properly prepared to teach diverse classrooms (Frideres, 2007, Dei, 2007; 2014A; Matias \& Mackey, 2016). As Gallagher (2014) argued, young people are currently facing the substantial negative effects of systemic inequality, which is demonstrated through their many challenges in the education system. This speaks to the Canadian education system's failure to address issues surrounding racial, social and cultural difference (James, 2012; Ghosh \& Galczynski, 2014, Dei, 2014a).

As the literature indicated, one of the ways to address the lack of knowledge surrounding topics of oppression, power and identity is through alternative pedagogical models that acknowledge difference as an integral part of the identities of both students and teachers (Dei, 2014a; Ghosh \& Galczynski, 2014). Further, several studies (Boal, 1979; Howard, 2004 Cahnmann-Taylor \& Souto-Manning, 2010; Gallagher, 2014; Desai, 2017) noted the value of performance as a critical pedagogical tool that can be utilized in the classroom to address more challenging topics such as identity, power and oppression.

Many of the practices used by participants are reflective of what the literature considers to be a form of performative critical pedagogy. The literature placed a focus on open dialogue, 
critical inquiry, problem-posing and collaboration between educators and students as the basis of critical performance-based learning (Freire, 1970; Boal, 1979; Fels \& Beliveau, 2008; Gallagher; 2014; Desai, 2017). All educators demonstrated these components of critical pedagogy through various performative activities. Sasha's work, for instance, strongly connected to Freire's (1970) notion of praxis through dialogue and problem solving based on generative themes. This is demonstrated through her use of the theme of change as an entry point for open dialogue with her students and as a basis for performative inquiry to ensue. Kaitlin was the only participant who directly referenced Boal's (1979) TO. However, the other educators' teaching practices exemplify the relationship between critical pedagogy and performance-based practices, suggesting that Boal's (1979) TO methods would be suitable to incorporate into their classrooms as well.

\section{Benefits of Performance-Based Practices with Youth}

The literature supported the findings from this study about the many benefits of incorporating performative methods with youth between the ages of 8 and 17 years of age. This included self-reflexivity, strengthened sense of self-confidence and agency, stronger analytical thinking skills and a heightened level of empathy for others (Fels \& Belliveau, 2008; CahnmannTaylor \& Souto-Manning, 2010; Gallagher, 2014). Several studies further noted the value in integrating performance-based teaching practices with youth, particularly when addressing issues surrounding power, identity, and oppression (Duffy, 2010; Gallagher; 2014; Desai, 2017). Specifically, all participants described the various ways in which this approach enabled their students to express and experiment with aspects of their identity in ways that they would not otherwise have the opportunity to do or not be encouraged to do in other areas of their lives. This was demonstrated through Greg's work where, through performance, marginalized students were 
able to demonstrate agency over their own identities in a playful and creative way which led to an increase in self-confidence and encouraged other students to learn about other narratives from the perspectives of students who may be different from themselves. Similarly, Sasha noted that many of her Black female students were able to able to explore their identity and culture through dance in ways that they had never been encouraged to do so before in an educational setting. This strongly suggests that the current Canadian education system is still embracing traditional discourses, which negate difference, systemic power imbalances and oppression entirely, as these students were keen to engage in a model that allowed their perspectives to be central to the learning experience (Boler \& Zembylas, 2003; Gallagher, 2014; Daniel, 2016).

Since each participant had practiced performance-based methods with students in their classrooms over a substantial length of time, they were able to observe the apparent benefits associated with these practices. Similar to the studies of Duffy (2010) and Gallagher (2014), it was found that through performance, students became more understanding of the ways in which social, cultural and racial differences are socially constructed and systemically reinforced through Canada's institutions. This led them to not only be more self-reflexive of their own potential privileges and biases but also to transform the ways in which they interacted with those whose identities were different from their own. Further, the literature revealed that through critical performative practices, students were able to problem-solve by imagining alternative realities of how things could be in their lives and experiment how they could take action and respond to different situations they might encounter outside of the classroom (Howard, 2004; Fels \& Belliveau, 2008; Gallagher, 2014; Duffy \& Powers; 2018). Kaitlin, demonstrated this using Forum Theatre to explore different oppressive scenarios with her students. Educators also noticed that as students continued to explore various issues and experience different situations 
through a variety of perspectives, they become better prepared to identify power imbalances and root causes of oppression (Cahnmann-Taylor \& Souto-Manning, 2010, Gallagher, 2014). For instance, Kaitlin's docu-drama unit with her classroom not only sparked a collective open dialogue on topics of race, oppression identity and power, but also prompted many of her White students to identify and reflect on instances where they engaged in problematic behaviour where these difficult topics were not properly respected within the classroom.

\section{Challenges Associated with Implementing Performance-Based Practices in the Classroom}

This study identified various challenges associated with implementing performancebased practices in the classroom with youth (Conrad, 2004; Fels \& Belliveau, 2008; SnyderYoung, 2011). Educators addressed both the difficulty of incorporating performative methods within the classroom from a logistical perspective, as well as the struggle to utilize these methods in order to teach students about issues related to difference, identity, power and oppression.

As various studies (Solomon \& Singer, 2011; Daniel, 2016) indicated, the preparation of teachers continuously negates the importance of equitable discourses and pedagogical practices. This is reflected in the findings as some of the White educators faced obstacles discussing issues surrounding difference in their classroom. Snyder-Young's (2011) study offered an example of the difficulties many White teachers face while attempting to address issues of race and oppression. Specifically, she struggled with discussing topics of social justice within her classroom, that was made up of predominantly non-White students from lower income families. She found that many of her students had opinions that conflicted with her perspective, specifically relating to issues surrounding gender identity, but did not want to invalidate anyone's opinion or centralize her own perspective, for fear of reinforcing notions of White dominance. 
This strongly connected to two of the main obstacles currently impeding the Canadian education system: the unwillingness of educators to learn and teach about White racial identity in an effective way and the disparities between a predominantly White teaching force and an increasingly diverse student population (Dei, 2007; 2014a; Daniel, 2016). Some participants agreed that it was difficult at times to negotiate their identities within their classroom, as none of them wanted to centralize their perspective over their students. Kaitlin's main challenge involved navigating how to effectively address issues of power and difference with students that were predominantly White, and therefore, needed to understand the critical role they play in dismantling systems of oppression and racism. Although Sasha and Nicole both experienced push back from school administrators, they did not express any concerns discussing issues surrounding oppression, identity and difference with their students. This further illustrates how students are eager to discuss subject matter that relates to them and suggests that they may have few opportunities to do explore these topics anywhere else.

\section{Feasibility of Implementing Performance-Based Practices}

The findings presented many similarities and some differences between the experience of educators and what the literature offered in terms of the feasibility of implementing performance-based practices within the classroom. The research suggested that the feasibility of implementing performance-based practices as a form of critical pedagogy within the classroom is largely dependent on educational policies, administrative agendas and educators' personal inclination to utilize performance-based methods in order to address issues of power, difference and oppression (Cahnmann-Taylor \& Souto-Manning, 2010; Duffy, 2010; Snyder-Young, 2011; Desai, 2017). In particular, the literature consistently highlighted the issue of teacher preparation as an obstacle to the feasibility of implementing critical performative methods within the 
classroom (Cahnmann-Taylor \& Souto-Manning, 2010; Duffy, 2010; Snyder-Young, 2011;

Schaedler, 2011; Desai, 2017). However, the findings demonstrated that it was feasible to implement performance-based practices within the classroom in instances where educators had a high level of control over their curriculum and daily routines as well as a passion for social justice and/or performance.

\section{Implications for Practice}

This research study has illuminated several implications educators should consider when implementing performance-based practices within their classroom, especially in instances where these methods are being used as a critical pedagogical tool to address issues of difference, oppression and power. First, it is important for educators to understand the importance of equitable learning and have a desire to maintain an anti-oppressive learning environment. In addition, educators should be committed to engaging in critical self-reflection in order to examine their own potential biases of others and assess their own privileges. The literature and findings suggested that educators should attempt to develop a thorough understanding of their students and their communities in order to better address their specific needs (Cahnmann-Taylor \& Souto-Manning, 2010; Solomon \& Singer, 2011; Daniel, 2016). Through sharing personal stories, and discussing sensitive topics, it is possible that students might disclose information that educators are not prepared to deal with, such as a traumatic experience or ongoing struggle at home. In instances where an educator does not feel knowledgeable about a particular topic or feels as though a student is suffering, they should seek out alternative resources to help support their students such as consulting a medical professional or arranging counselling for their student. 
Educators should strive to be mindful of the fact that all students differ greatly in terms of their lived experiences, identities, and abilities. They should therefore, orient their teaching practices in a way that would best address their students' needs and highlight their perspectives. Further, the findings suggested that it is valuable for educators using performance-based methods to constantly explore different ways to connect with their students and engage their classroom in open critical discussion. Including performance-based practices in the classroom provides students with the opportunity to address a wide variety of subject matter in a playful and relaxed manner. (Howard, 2004; Fels \& Belliveau, 2008; Cahnmann-Taylor \& Souto-Manning, 2010; Gallagher, 2014; Desai, 2017). This further allows them to practice being in different situations and responding to various issues that they may encounter outside of the classroom. It is possible that the opinions of young students between the ages of 8-17 are not necessarily politically or socially progressive in a way that aligns with the educator's agenda. Educators should take time to develop a way of addressing students' problematic assumptions in a way that does not undermine their voice.

Although not outlined in the literature, all participants found that growing mental health concerns posed a challenge to students' learning processes. They unanimously agreed that performance, although sometimes challenging to implement with students struggling with their mental health, can actually help to alleviate symptoms of anxiety by providing students with an outlet to discuss their feelings as well as topics that strongly resonate with them. This further speaks to bell hooks' $(1994 ; 2003)$ notion of engaged pedagogy where the holistic well-being of students is central to their capacity to learn and engage within the classroom. 


\section{Limitations to the Study and Directions for Further Research}

The findings of this study were limited by a narrow sample size and therefore cannot be representative of a larger, generalized population. Although participants were contacted early into the research process, it was challenging to recruit a large sample of participants. Given the high level of experience needed from eligible participants, some respondents were not included in the study as they did not meet the necessary requirements. Since the recruitment process took place near March Break and mid-term exams, it is possible that educators felt overwhelmed and were too busy finishing up final projects to volunteer their time. In addition, all participants had over 10 years of experience using performance-based methods with youth and were currently employed in Southern Ontario. Of particular significance to this study was the homogeneity of educators. The sample was reflective of the current lack of racial diversity in the Canadian education system as only one non-White educator participated. A larger sample size would potentially bring in a more diverse range of participants

Interviewing youth between the ages 8-17 years old in classrooms where performancebased practices are implemented would further benefit this research. The various unique perspectives of students could be shared through interviews in order to develop a more thorough and honest understanding of their views towards performance-based practices and their overall learning experience. It would also be of value to hear, first-hand from youth, what kind of topics or issues resonate with them, as one of the main focuses of critical performative pedagogy is centralizing the voice of the student. These adjustments to the recruitment and interview process could be valuable to the research on performance-based practices with youth and its potential to serve as a critical pedagogical tool in the teaching of racial, social and cultural difference. 


\section{Appendix A: Email Message}

Email message to contacts in Dr. Binder's network:

Dear

I am currently supervising a graduate student, Madison Gaudry-Routledge, for her master's research paper entitled, "Effects of Performance-Based Methods in Teachings of Difference with Youth." I am able to assist in the recruitment process by asking if you are at all interested in participating in her study. In your work in drama education you may be practicing performance based teaching methods with students. She is looking for four to six participants to take part in a 45-60-minute interview. Madison is specifically looking at teachers from Grade Three classrooms to High School. She will ask you questions such as: Please explain how performance methods, such as drama, dance, etc. has been incorporated into your teaching of youth; How do you use performance-based methods when teaching youth on topics of difference?

Confidentiality will be ensured by immediately assigning pseudonyms as well as storing all data in a locked cabinet in my office.

If interested please email Madison Gaudry-Routledge at mgaudryr@ryerson.ca and she will send you a recruitment letter that explains the research study further, and if you decide to participate, a letter of consent will be sent to you to sign. Madison will also be able to answer any questions you have.

This study has been reviewed and approved by the Ryerson University Research Ethics Board (REB 2017-376). If you have questions regarding your rights as a participant in this study please contact:

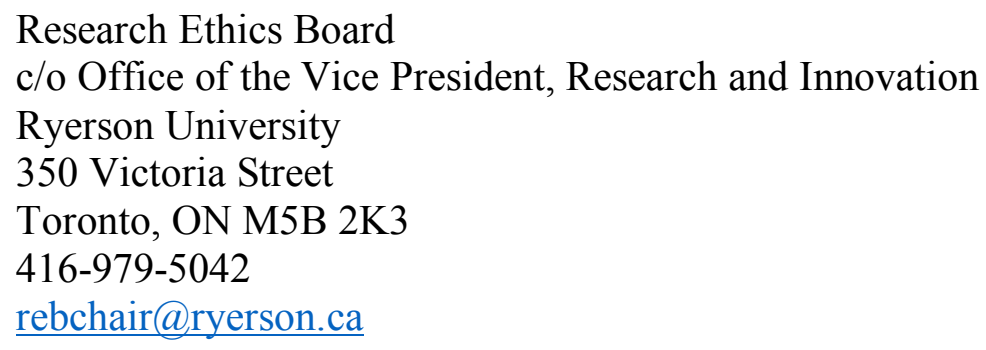

Participation is voluntary. If you choose not to participate in this study, it will not affect your relationship with me or Ryerson University.

Sincerely,

Dr. Marni Binder 


\section{Appendix B: Email Message for Participant Recruitment from the Council of Ontario Drama and Dance Educators (CODE)}

Dear CODE members,

I am currently supervising a graduate student, Madison Gaudry-Routledge, in the Communications and Culture program at Ryerson for her Master's Research Paper entitled, "Effects of Performance-Based Methods in Teachings of Difference with Youth." I am able to assist in the recruitment process by asking if you are at all interested in participating in her study. In your work in drama education you may be practicing performance based teaching methods with students. She is looking for four to six participants to take part in a 45-60-minute interview. Madison is specifically looking at teachers from Grade Three classrooms to High School. She will ask you questions such as: Please explain how performance methods, such as drama, dance, etc. has been incorporated into your teaching of youth; How do you use performance-based methods when teaching youth on topics of difference?

Confidentiality will be ensured by immediately assigning pseudonyms as well as storing all data in a locked cabinet in my office.

If interested please email Madison Gaudry-Routledge at mgaudryr@ryerson.ca and she will send you a recruitment letter that explains the research study further, and if you decide to participate, a letter of consent will be sent to you to sign. Madison will also be able to answer any questions you have.

This study has been reviewed and approved by the Ryerson University Research Ethics Board (REB 2017-376). If you have questions regarding your rights as a participant in this study please contact:

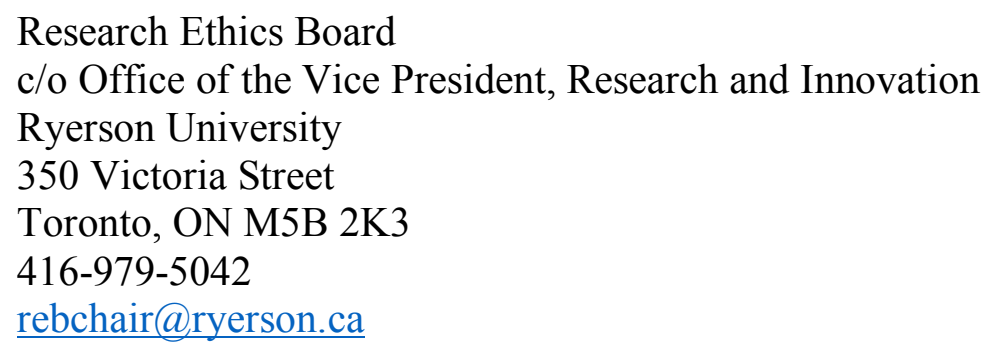

Participation is voluntary. If you choose not to participate in this study, it will not affect your relationship with me or Ryerson University.

Sincerely,

Dr. Marni Binder

School of Early Childhood Studies

Ryerson University

350 Victoria Street, Toronto ON, Canada M5B 2K3

Tel: 416-979-5000, ext. 7130

mbinder@ryerson. 


\section{Appendix C: Email message from Madison Gaudry-Routledge to potential participants}

Dear

My name is Madison Gaudry-Routledge and I am a student in the Masters of Communication and Culture program at Ryerson University. For my Masters Research Paper, I am exploring the pragmatic ways in which individuals, particularly youth ages 8-17, are taught within the Canadian education system, specifically Ontario, on topics of racial difference, and how this influences their understanding of the construction of identity, and the systemic oppression of marginalized groups.

I am conducting research for my study entitled "Effects of Performance-Based Methods in Teachings of Difference with Youth." I am recruiting four to six educators who are using or have used performance-based teaching methods with youth between the ages 8-17. There will be one interview for approximately 45-60 minutes. I will collect all information through audiorecording and notetaking in a research journal. I will ask questions about performance practices and theory in your daily life and when working with youth in your teaching. Some questions include: Please explain how performance methods, such as drama, dance, etc. has been incorporated into your teaching of youth; How do you use performance-based methods when teaching youth on topics of difference? Through this interview I hope to add to the existing discourse in the area of North American education.

I have attached a recruitment letter and consent letter for your consideration. Participation is voluntary. Confidentiality will be ensured by immediately assigning pseudonyms as well as storing all data in a locked cabinet in my supervisor's office.

This study has been reviewed and approved by the Ryerson University Research Ethics Board (REB 2017-376). If you have questions regarding your rights as a participant in this study please contact:

Research Ethics Board c/o Office of the Vice President, Research and Innovation Ryerson University 350 Victoria Street, Toronto, ON M5B 2K3

Tel: 416-979-5042

rebchair@ryerson.c

If you have any questions you may contact me at: mgaudryr@,ryerson.ca or my supervisor Dr. Marni Binder at:

Dr. Marni Binder

School of Early Childhood Studies

Ryerson University

350 Victoria Street, Toronto ON, Canada M5B 2K3

Tel: 416-979-5000, ext. 7130 mbinder@,ryerson.ca

Thank you.

Sincerely, Madison Gaudry - Routledge 


\section{Appendix D: Recruitment Letter}

\section{Ryerson}

University

\section{Advertisement for Recruitment of Study Participants}

\section{Are you interested in participating in a study that explores the effects of performance- based teaching methods with youth?}

Research Title: Effects of Performance-Based Methods in Teachings of Difference with Youth

My name is Madison Gaudry-Routledge and I am a student in the Masters of Communication and Culture program at Ryerson University. For my Masters Research Paper, I am exploring the pragmatic ways in which individuals, particularly youth ages 8-17, are taught within the Canadian education system, specifically Ontario, on topics of racial difference, and how this influences their understanding of the construction of identity, and the systemic oppression of marginalized groups. I propose that one way to address this issue of institutionalized white normativity within the education system is through the incorporation of performative pedagogical approaches to the teachings of difference. This study will look at the effects of performance-based teaching practices with youth in a variety of learning environments.

I would like to interview four to six educators who are using or have used performance-based teaching methods with youth between the ages 8-17. There will be one interview for approximately 45-60 minutes. I will collect all information through audio-recording and notetaking in a research journal. I will ask questions about performance practices and theory in your daily life and when working with youth in your teaching. Some questions include: Please explain how performance methods, such as drama, dance, etc. has been incorporated into your teaching of youth; How do you use performance-based methods when teaching youth on topics of difference? Through this interview I hope to add to the existing discourse in the area of North American education. Particularly, alternative pedagogical practices aimed at promoting equitable education, education policy, and issues of representation, identity and inclusion within the education system will be examined in my Masters Research Paper. I also hope to gain more of a sufficient understanding of how performance-based teaching methods impact youth in understanding their own identity as well as the identities of those who are different from them. I feel that your experiences of using these methods in an educational environment would provide insight into the effects these techniques have on youth.

Participation is completely voluntary. If you choose to volunteer to be in this study, you may withdraw at any time without consequence of any kind. You may also choose not to answer any question(s) and still remain in the study. Your decision of whether or not to participate will not influence your future relations with myself, Dr. Marni Binder, or Ryerson University. A potential risk of this study may include emotional discomfort from the interview questions. Confidentiality will be maintained through the immediate use of a pseudonym and data will be kept in a locked cabinet in my supervisor's office. 
This study has been reviewed and approved by the Ryerson University Research Ethics Board (REB 2017-376). If you have questions regarding your rights as a participant in this study please contact:

Research Ethics Board

c/o Office of the Vice President, Research and Innovation

Ryerson University

350 Victoria Street

Toronto, ON M5B 2K3

416-979-5042

rebchair@ryerson.ca

If you would like more information about this study or how to participate, you may contact me at mgaudryr@ryerson.ca or Dr. Marni Binder at:

Dr. Marni Binder

School of Early Childhood Studies

Ryerson University

350 Victoria Street

Toronto ON, Canada M5B 2K3

Tel: 416-979-5000, ext. 7130

mbinder@ryerson.ca

Sincerely,

Madison Gaudry Routledge

mgaduryr@ryerson.ca 


\section{Appendix E: Consent Letter}

\section{Ryerson \\ University}

\section{Ryerson University Consent Agreement}

You are being invited to participate in a research study. Please read this consent form so that you understand what your participation will involve. Before you consent to participate, please ask any questions to be sure you understand what your participation will involve.

Title of Study: Effects of Performance-Based Methods in Teachings of Difference with Youth Study

\section{INVESTIGATORS:}

This research study is being conducted by Madison Gaudry-Routledge, a Masters Student from the Faculty of Communication and Culture, Ryerson University, Toronto Canada.

The supervisor of this study is Dr. Marni Binder from the School of Early Childhood Studies, Ryerson University, Toronto Canada. She may be contacted at:

Dr. Marni Binder

School of Early Childhood Studies

Ryerson University

350 Victoria Street

Toronto ON, Canada M5B 2K3

Tel: 416-979-5000, ext. 7130

mbinder@,ryerson.ca

If you have any questions or concerns about the research, please feel free to contact: Madison Gaudry-Routledge at mgaudryr@,ryerson.ca

\section{PURPOSE OF THE STUDY:}

This study aims to explore the pragmatic ways in which individuals, particularly youth ages 817, are taught within the Canadian education system, specifically Ontario, on topics of racial difference, and how this influences their understanding of the construction of identity, and the systemic oppression of marginalized groups. I propose that one way to address this issue of institutionalized white normativity within the education system is through the incorporation of performative pedagogical approaches to the teachings of difference. I am interested in exploring different educator's experiences in facilitating these practices. Through interviewing educators, I will learn more about how performance-based methods can be practiced with youth and the various effects it has. 
There will be one interview for approximately 45-60 minutes. I will ask questions about performance-based practices in your daily life and when working with youth. I would like to hear your stories and learn the effects of performance-based practices when addressing topics of social difference. What I learn from your interviews will help me to gain an understanding of how performance-based teaching methods impact youth in understanding their own identity and the identities of those who are different from them. I will be audio recording the interview and making notes throughout.

\section{WHAT PARTICIPATION MEANS:}

If you volunteer to participate in this study, you will be asked to do the following things:

- Participate in one 45-60-minute interview that will be audio-recorded in a location of your choice. (This may include a public library, community center, or the researcher can book a room at Ryerson University)

\section{Example of Interview Questions}

1. When did you become involved in the study or practice of drama education? Performance?

2. How has performance, such as drama, dance, etc. been incorporated into your teaching of youth?

\section{Personal Information}

I will ask for some information about you. For example:

- How long have you been practicing drama and/or performance-based teaching methods with youth?

- In what kinds of environments have you worked with youth?

\section{Research Findings}

I will supply you with a transcription of the interview for verification via email. I will also provide you with a finalized copy of the Major Research Paper upon completion.

\section{POTENTIAL BENEFITS:}

This research could potentially benefit participants as it provides an opportunity to share the importance of drama education in teaching and learning, specifically performance-based pedagogical practices. Discussing how this contributes to the learning of children and/or youth around topics of difference and their overall well-being offers a unique opportunity to discuss the importance of teaching through the arts. However, I cannot guarantee, that you will receive any benefits from participating in this study.

\section{WHAT ARE THE POTENTIAL RISKS TO YOU AS A PARTICIPANT:}

Potential risks involved in this study are very low. However potential risks of this study may include possible feelings of emotional discomfort. Due to the personal nature of the questions asked involving participants' experience with teaching children about potentially upsetting 
topics, such as discrimination, a participant might reflect on unpleasant memories while responding in the interview. The participant should be aware that if he/she feels uncomfortable at any time of the interview, he/she may skip answering a question or stop participation, either temporarily or permanently. If you choose to stop participating in the interview, this will not affect the relationship with myself, the School of Early Childhood Studies, or Ryerson University. Any data collected will be safely destroyed at that time.

\section{CONFIDENTIALITY:}

The only people who will have access to all data collected are myself and my supervisor, Dr. Marni Binder. All data (audio-recordings, transcripts) will be stored on a secure password protected USB key and will be stored in Dr. Binder's office at Ryerson University. The data will be kept for one year after completion of the Major Research Paper and then destroyed. As a participant, you have the right to hear the interviews and see the transcriptions. Confidentiality will only be breached if you reveal indications of harm to yourself or others. If any mention of child abuse or neglect is mentioned during the interview I am under duty to report.

\section{INCENTIVES FOR PARTICIPATION:}

No payment is being offered to take part in the study.

\section{COSTS TO PARTICIPATION:}

There should be no cost to the participant as the study will take place at a place and time that is convenient for the participant.

\section{VOLUNTARY PARTICIPATION AND WITHDRAWAL:}

Participation in this study is completely voluntary. You can choose whether to be in this study or not. If any question makes you uncomfortable, you can skip that question. You may stop participating at any time and you will still be given the incentives and reimbursements described above. If you choose to stop participating, you may also choose to not have your data included in the study. Your choice of whether or not to participate will not influence your future relations with Ryerson University, York University, myself, or Dr. Marni Binder.

QUESTIONS ABOUT THE STUDY: If you have any questions about the research now, please ask. If you have questions later about the research, you may contact me at mgaudryr@ryerson.ca

This study has been reviewed and approved by the Ryerson University Research Ethics Board (REB 2017-376). If you have questions regarding your rights as a participant in this study please contact:

Research Ethics Board c/o Office of the Vice President, Research and Innovation Ryerson University, 350 Victoria Street, Toronto, ON M5B 2K3

Tel: 416-979-5042 rebchair@ryerson.ca 


\section{EFFECTS OF PERFORMANCE-BASED METHODS IN TEACHINGS OF DIFFERENCE WITH YOUTH STUDY}

\section{CONFIRMATION OF AGREEMENT:}

Your signature below indicates that you have read the information in this agreement and have had a chance to ask any questions you have about the study. Your signature also indicates that you agree to participate in the study and have been told that you can change your mind and withdraw your consent to participate at any time. You have been given a copy of this agreement. You have been told that by signing this consent agreement you are not giving up any of your legal rights.

Name of Participant (please print)

Signature of Participant

Date

I agree to be audio-/video recorded for the purposes of this study. I understand how these recordings will be stored and destroyed.

Signature of Participant

Date 


\section{Appendix F: Interview Guide}

Ryerson

University

\section{Interview Guide: Effects of Performance-Based Methods in Teachings of Difference with Youth Study}

1. When did you become involved in the study or practice of theatre/drama/ performancebased art?

2. What, specifically, about this practice resonated with you?

3. How have you incorporated performance-based methods into your teaching practices?

4. How long have you been teaching in drama education and/ or using performance-based teaching methods with youth?

5. In what kinds of environments have you worked with youth?

6. Can you provide detail on specific drama exercises you have used?

7. What topics have you used performance-based teaching methods for? Have you ever used these methods to discuss issues of identity or social justice?

8. Can you please describe an instance where you used performance-based methods to have a student open up or address a topic they were struggling with?

9. What effects do you feel performance-based methods has on youth, particularly when addressing issues of difference? Are the effects generally positive or negative? Why do you think this might be?

10. Do you think your own experiences have influenced the ways in which you go about teaching? In what ways have your own experiences shaped your current teaching style? 
11. Would more drama and performance-based methods be a useful tool in teaching students in other areas of study? What subjects or topics, are these methods particularly useful for? Why? 


\section{References}

Abada, T., \& Lin, S. (2011). The educational attainments and labour market outcomes of the children of immigrants in Ontario. Toronto, ON, Canada: Higher Education Quality Council of Ontario.

Ash, M. C. T. (2004). But where are you REALLY from? Reflections on immigration, multiculturalism and Canadian identity. In C.A. Nelson \& C.A. Nelson (Eds.), Racism eh? A critical inter-disciplinary anthology of race and racism in Canada (pp. 398-409). Concord, ON: Captus Press.

Boal, A. (1979). Theatre of the oppressed. New York, NY: Theatre Communications Group.

Boler, M., \& Zembylas, M. (2003). Discomforting truths: The emotional terrain of understanding difference. In P. Trifonas (Ed.), Pedagogies of difference: Rethinking education for social change (pp.107-130). New York, NY: Routledge Falmer.

Bourdieu, P., \& Passeron, J.C. (1992). Reproduction in education, society and culture. (2 ${ }^{\text {nd }}$ ed.). London, UK: Sage.

Braun, V., \& Clarke, V. (2006). Using thematic analysis in psychology. Qualitative Research in Psychology, 3(2), 77-101.

Cahnmann-Taylor, M. (2006). Reading, living, and writing bilingual poetry as schoolARTistry in the language arts classroom. Language Arts, 83(4), 341-351.

Cahnmann-Taylor, M., \& Souto-Manning, M. (2010). Teachers act up! Creating multicultural learning communities through theatre. New York, NY: Teachers College Press.

Caldas, S., Bernier, S., \& Marceau, R. (2009). Explanatory factors of the black achievement gap in Montréal's public and private schools: A multivariate analysis. Education and Urban Society, 41(2), 197-215. 
Carr, P.R., \& Lund, D.E. (Eds.). (2007). The great white north: Exploring whiteness, privilege, and identity in education. Rotterdam, The Netherlands: Sense Publishers.

Carr, P.R., \& Lund, D. E. (Eds.). (2014). Revisiting the great white north? Reframing whiteness, privilege, and identity in education (Second edition). Rotterdam, The Netherlands: Sense Publishers.

Codjoe, H. (2006). The role of an affirmed black cultural identity and heritage in the academic achievement of African-Canadian students. Intercultural Education, 17(1), 33-54.

Cohn, D. (2016, June 16). It's official: Minority babies are the majority among the nation's infants, but only just. Retrieved from: http://pewrsr.ch/28UIGZG

Comeau, L. (2007). Re-inscribing whiteness through progressive constructions of "the problem" in anti-racist education. In P.R Carr \& D.E. Lund (Eds.), Revisiting the great white north? Exploring whiteness, privilege and identity in education (pp. 151-160). Rotterdam, The Netherlands: Sense Publishers.

Conrad, D. (2004). Popular theatre: Empowering pedagogy for youth. Youth Theatre Journal, 18(1), 87-106. doi: 10.1080/08929092.2004.10012566

Conrad, D. (2005). Rethinking 'at-risk' in drama education: Beyond prescribed roles. Research in Drama Education: The Journal of Applied Theatre and Performance, 10(1), 27-41. doi:10.1080/13569780500053114

Crenshaw, K. (1991). Mapping the margins: Intersectionality, identity politics and violence against women of color. Stanford Law Review, 43, 1241-1299.

Crenshaw, K., Gotanda, N., Peller, G., \& Thomas, K. (1995). Critical race theory: The key writings that formed the movement. New York, NY: The New Press. 
Creswell, J. W. (2008). Educational research: planning, conducting, and evaluating quantitative and qualitative research. Upper saddle River, NJ: Pearson Education, Inc.

Creswell, J. W. (2014). Research design: Qualitative, quantitative, and mixed methods approaches. Thousand Oaks, CA: SAGE Publications, Inc.

Daniel, B.M. (2016). Diversity, justice, and community: The Canadian context. Toronto, ON, Canada: Canadian Scholars' Press, Inc.

Davis, R., \& Freire, P. (1981). Education for awareness. In R. Mackie (Ed.), Literacy and revolution (pp.57-69). New York, NY: The Continuum Publishing Company.

Davis, T., Harrison, L. M., \& Roper, L.D. (2013). Advancing social justice: Tools, pedagogies, and strategies to transform your campus. San Francisco, CA: Jossey-Bass.

Day, R. J. F. (2000). Multiculturalism and the history of Canadian diversity Toronto, ON, Canada: University of Toronto Press.

Dei, G. J. S. (2007). Foreword to the first edition. In P.R Carr \& D.E. Lund (Eds.), Revisiting the great white north? Exploring whiteness, privilege and identity in education (pp. vvii-xii). Rotterdam, The Netherlands: Sense Publishers.

Dei, G., J. (2014a). Personal reflections on anti-racism education for a global context. Encounters on Education, 15, 239-249. http://dx.doi.org.ezproxy.lib.ryerson.ca/10.15572/ENCO2014.13

Dei, G.S. (2014b). Foreword to the second edition. In D.E. Lund \& P.R. Carr (Eds.), Revisiting the great white north: Reframing whiteness, privilege and identity in education ( $\left.2^{\text {nd }} \mathrm{ed}.\right)$ (pp. xix-xxiii). Rotterdam, Netherlands: Sense Publishers.

Delgado, R., \& Stefancic, J. (2017). Critical race theory: An introduction. New York, NY: NYU Press. 
Desai, S.R. (2017). Utilizing theatre of the oppressed within teacher education to create emancipatory teachers. Multicultural Perspectives, 19(4), 229-233. doi: $10.1080 / 15210960.2017 .1347875$

Dill, B. T., \& Zambrana, R. E. (2009). Critical thinking about inequality: An emerging lens. In B.T. Dill \& R.E. Zambrana (Eds.), Emerging intersections: Race, class, and gender in theory, policy, and practice (pp.1-21). New Brunswick, N.J: Rutgers University Press.

Doxtator, D. (2011). "The idea of Indianness" and once upon a time: The role of Indians in history. In M.J. Cannon \& L. Sunseri (Eds.), Racism, colonialism and indigeneity in Canada (pp.31-36). Toronto, ON, Canada: Oxford University Press.

Duffy, P., \& Vettraino, E. (2010). Foreword. In P. Duffy \& E. Vettraino (Eds.), Youth and theatre of the oppressed (pp. xiii). New York, NY: Palgrave Macmillan.

Duffy, P. (2010). Staying alert: A conversation with Chris Vine. In P. Duffy \& E. Vettraino (Eds.), Youth and theatre of the oppressed (pp.187-262). New York, NY: Palgrave Macmillan.

Duffy, P., \& Powers, B. (2018). Blind to what's in front of them: Theatre of the oppressed and t teacher reflexive practice, embodying culturally relevant pedagogy with pre-service teachers. Youth Theatre Journal, 32(1), 45. doi:10. 1080/08929092.2018.1445677

Fels, L., \& Belliveau, G. A. (2008). Exploring curriculum: Performative inquiry, role drama, and learning. Vancouver, B.C., Canada: Pacific Educational Press.

Freire, P. (1970). Pedagogy of the oppressed. New York, NY: Continuum.

Freire, P. (1985). The politics of education. Westport, CT: Bergin \& Garvin. 
Freire, P. (1997). A response. In P. Freire, with J. W. Fraser, D. Macedo, T. McKinnon, \& W.T. Stokes (Eds.) Mentoring the mentor (pp. 303-329). New York, NY: Peter Lang.

Freire, P. (1998). Pedagogy of freedom (P. Clarke, Trans. 2001 ed.). New York, NY: Rowman and Littlefield Publishers Inc.

Frideres, J. (2007). Re-inscribing whiteness through progressive constructions of "the problem" in anti-racist education. In P.R Carr \& D.E. Lund (Eds.), Revisiting the great white north? Exploring whiteness, privilege and identity in education (pp. 43-57). Rotterdam, The Netherlands: Sense Publishers.

Gallagher, K. (2002). Drama education in the lives of girls. Toronto, ON, Canada: University of Toronto Press.

Gallagher, K. (2014). Why theatre matters: Urban youth, engagement, and a pedagogy of the real. Toronto: University of Toronto Press, Scholarly Publishing Division.

Galletta, A., \& Cross, W.E. (2013). Mastering the semi-structured interview and beyond: From research design to analysis and publication. New York, NY: New York University Press.

Ghosh, R., \& Galczynski, M. (2014). Redefining multicultural education: Inclusion and the right to be different. Toronto, ON, Canada: Canadian Scholars' Press.

Giard, M. (2005). Mitakuye Oyas 'in: Performing trauma to strength. Unpublished doctoral Dissertation. University of British Columbia, Vancouver, British Columbia, Canada.

Giroux, H. (1997). Pedagogy and the politics of hope: Theory, culture, and schooling: A critical reader. New York, NY: Routledge.

Giroux, H.A. (2011). On critical pedagogy. In A. Freire \& S.R. Steinberg (Eds.) New York, NY: Continuum International Publishing Group. 
Grbich, C. (2013). Qualitative data analysis: An introduction. (2 ${ }^{\text {nd }}$ Ed.). Thousand Oaks, CA: Sage.

Hạnh, T. N. (1987). The miracle of mindfulness: An introduction to the practice of meditation. Boston, MA: Beacon Press.

Harman, R., \& French, K. (2004) Critical performance pedagogy: A feasible praxis for teacher education. In J. O’Donnell, M. Pruyn, \& R.C. Chavez (Eds.), Social justice in these times (pp. 97-115). Charlotte, NC: Information Age Publishing.

hooks, b. (1994). Teaching to transgress. New York, NY: Routledge hooks, b. (2003). Teaching community: Pedagogy of hope. New York, NY: Routledge.

Howard, L. A. (2004). Speaking theatre/doing pedagogy: Re-visiting theatre of the oppressed. Communication Education, 53(3), 217-233. doi:10.1080/0363452042000265161

Howard, G. R. (2006). We can't teach what we don't know: White teachers, multiracial schools. New York, NY: Teachers College Press.

Jablonski, N. G. (2012). Living color: The biological and social meaning of skin color. Berkeley, CA: University of California Press.

James, C. E. (2009). Masculinity, racialization, and schooling: The making of marginalized men. In W. Martino, M. Kehler, \& M. B. Weaver-Hightower (Eds.), The problem with boys' education: Beyond the backlash (pp. 102-123). New York, NY: Routledge.

James, C.E. (2012). Students "at risk": Stereotypes and the schooling of black boys. Urban Education, 47 (92), 464-494.

Kincheloe, J. L. (2005). Critical constructivism primer. New York, NY: Peter Lang.

King, N., \& Horrocks, C. (2010). Interviews in qualitative research. London, UK: Sage Publications. 
Lang, L. (1999). "To open our minds more freely": Educational drama and the common curriculum framework for English language arts. English Quarterly, 31(3 \& 4), 48-62.

Lankshear, C., McLaren, P., \& Kincheloe, J. (Eds.). (1994). The politics of liberation: paths from Freire. New York, NY: Routledge.

Levin, B. (2004). Students at-risk: A review of research. Educator's Notebook: Reviews of Research of Interest to Educators, 15(3), 1-4.

Lipman, P. (2011). Contesting the city: Neoliberal urbanism and the cultural politics of education reform in Chicago. Discourses: Studies in the Cultural Politics of Education, 32(2), $217-$ 234.

Matias, C.E., \& Mackey, J. (2016). Breakin' down whiteness in antiracist teaching: Introducing critical whiteness pedagogy. The Urban Review, 48(1), 32-50. doi: 10. 1007/s11256-0150344-7

Portelli, J. (2011). Preface. In R.P. Solomon, J. Singer, A. Campbell \& A. Allen (Eds.), Brave new teachers: Doing social justice work in neo-liberal times (pp. vii-xii). Toronto, ON, Canada: Canadian Scholars' Press. Inc.

National Collaborative on Diversity in the Teaching Force. (2004). Assessment of diversity in America's teaching force: A call to action. Washington, DC: The Author. Retrieved June 1, 2018, from http://www.ate1.org/pubs /uploads/diversityreport.pdf

Olson, K. (2011). Essentials of qualitative interviewing. Walnut Creek, CA: Routledge. Ryan, J., Pollock, K., \& Antonelli, F. (2009). Teaching diversity in Canada: Leaky pipelines, bottlenecks, and glass ceilings. Canadian Journal of Education/ Revue Canadienne De l'Education, 32(3), 591-617. 
Salojee, A. (2004). Social cohesion and the limits of multiculturalism in Canada. In C.A. Nelson \& C.A. Nelson (Eds.), Racism eh? A critical inter-disciplinary anthology of race and racism in Canada (pp. 410-428). Concord, ON, Canada: Captus Press.

Sandelowski, M. (2000). Whatever happened to qualitative description? Research in Nursing \& Health, 23(4), 334-340.

Schaedler, M.T. (2010). Boal's theater of the oppressed and how to derail real-life tragedies with imagination. New Directions for Youth Development, 2010(125), 141-151.

Shor, I., \& Freire, P. (1987). A pedagogy for liberation. South Hadley, MA: Bergin \& Garvey Publishers.

Shor, I. (1992). Empowering education: Critical teaching in social change. Chicago, IL: The University of Chicago Press.

Sleeter, C. E. (2001). Preparing teachers for culturally diverse schools. Journal of Teacher Education, 52, 94-106.

Snyder-Young, D. (2011). Rehearsals for revolution? Theatre of the Oppressed, dominant discourses, and democratic tensions. Research in Drama Education, 16(1), 29-45.

Solomon, R.P., \& Singer, J. (2011). Introduction: Distinguishing our present context: The meaning of diversity in education for social justice. In R.P. Solomon, J. Singer, A. Campbell \& A. Allen (Eds.), Brave new teachers: Doing social justice work in neoliberal times (pp.1-29). Toronto, ON, Canada: Canadian Scholars' Press. Inc.

Souto-Manning. (2009). Negotiating culturally responsive pedagogy through multicultural children's literature: Towards critical democratic literacy practices in a first grade classroom. Journal of Early Childhood Literacy, 9(1), 53-77. 
Stovall, D. (2013). Against the politics of desperation: Educational justice, critical race theory, and Chicago school reform. Critical Studies in Education, 54(1), 33-43.

Thompson, G. (2009, March 14). Where education and assimilation collide. The New York Times. Retrieved from https://www.nytimes.com/2009/03/15/us/15immig.html

Trifonas, P.P. (Ed.). (2003). Pedagogies of difference: Rethinking education for social change. New York, NY: Routledge Falmer.

UNICEF Office of Research. (2013). Child well-being in rich countries: A comparative overview (Innocenti Report Card 11 1-60). Florence, ITL: UNICEF Office of Research. Retrieved from https://www.unicef-irc.org/publications/pdf/rc11_eng.pdf

Wotherspoon, T., \& Schissel, B. (2001). The business of placing Canadian children and youth “at-risk." Canadian Journal of Education, 26(3), 321-339. 